PNNL-13644

Phase 2

NUCLEAR ENERGY RESEARCH INITIATIVE

\title{
NOVEL CONCEPTS FOR DAMAGE-RESISTANT ALLOYS IN NEXT GENERATION NUCLEAR POWER SYSTEMS
}

\author{
Phase 2 Annual Report
}

\section{Pacific Northwest National Laboratory}

S. M. Bruemmer and E. P. Simonen, Principal Investigators

F. A. Garner

D. J. Edwards

J. Gan

General Electric Corporate Research \& Development

P. L. Andresen

University of Michigan

G. S. Was

August 31, 2001

Prepared for:

U.S. Department of Energy

Oakland Operations Office 1301 Clay Street

Oakland, CA 94612

Attn: Philip Wong, NSPD

U.S. Department of Energy

Office of Nuclear Energy, Science and Technology

19901 Germantown Road

Germantown, MD 20874

Attn: Frank Ross, NE-20

Pacific Northwest National Laboratory

Richland, Washington 99352 


\title{
DISCLAIMER
}

This report was prepared as an account of work sponsored by an agency of the United States Government. Neither the United States Government nor any agency thereof, nor Battelle Memorial Institute, nor any of their employees, makes any warranty, express or implied, or assumes any legal liability or responsibility for the accuracy, completeness, or usefulness of any information, apparatus, product, or process disclosed, or represents that its use would not infringe privately owned rights. Reference herein to any specific commercial product, process, or service by trade name, trademark, manufacturer, or otherwise does not necessarily constitute or imply its endorsement, recommendation, or favoring by the United States Government or any agency thereof, or Battelle Memorial Institute. The views and opinions of authors expressed herein do not necessarily state or reflect those of the United States Government or any agency thereof.

\author{
PACIFIC NORTHWEST NATIONAL LABORATORY \\ operated by \\ BATTELLE \\ for the \\ UNITED STATES DEPARTMENT OF ENERGY \\ under Contract DE-AC06-76RL01830
}

Ty 
PNNL-13644

Phase 2

NUCLEAR ENERGY RESEARCH INITIATIVE

\title{
NOVEL CONCEPTS FOR DAMAGE-RESISTANT ALLOYS IN NEXT GENERATION NUCLEAR POWER SYSTEMS
}

\author{
Phase 2 Annual Report
}

\section{Pacific Northwest National Laboratory}

S. M. Bruemmer and E. P. Simonen, Principal Investigators

F. A. Garner

D. J. Edwards

J. Gan

General Electric Corporate Research \& Development

P. L. Andresen

University of Michigan

G. S. Was

August 31, 2001

Prepared for:

U.S. Department of Energy

Oakland Operations Office 1301 Clay Street

Oakland, CA 94612

Attn: Philip Wong, NSPD

U.S. Department of Energy

Office of Nuclear Energy, Science and Technology

19901 Germantown Road

Germantown, MD 20874

Attn: Frank Ross, NE-20

Pacific Northwest National Laboratory

Richland, Washington 99352 


\section{TABLE OF CONTENTS}

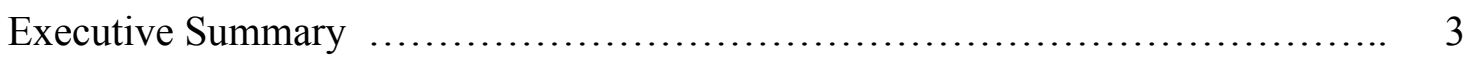

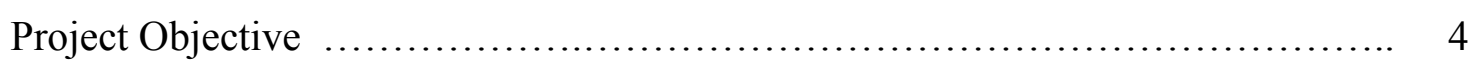

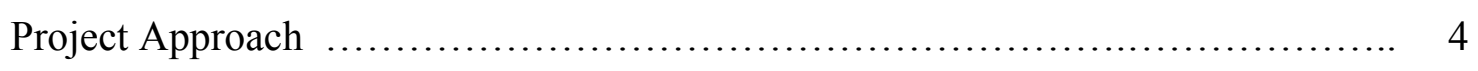

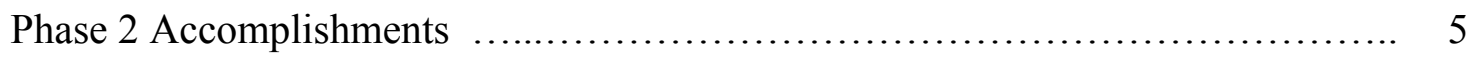

Task 2a: Materials Processing ....................................... 5

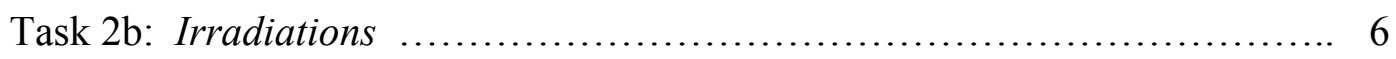

Task 2c: Materials Characterizations ................................ 6

Task 2d: Mechanical Behavior and Stress Corrosion Cracking ............ 7

Publications......................................................... 7

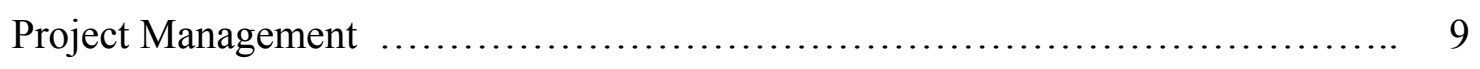

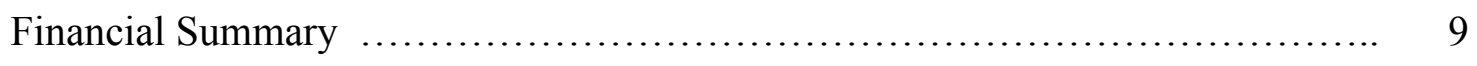

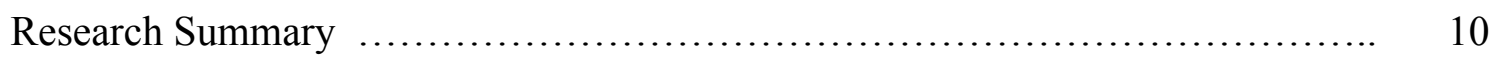

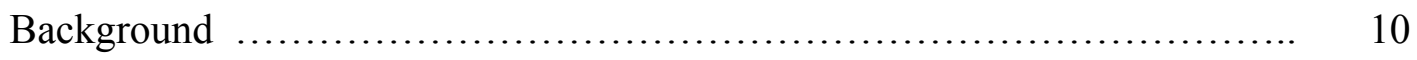

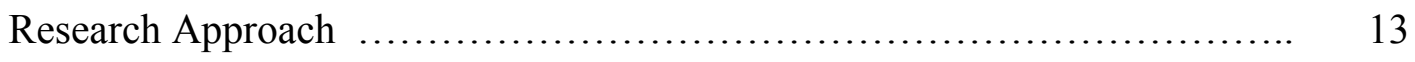

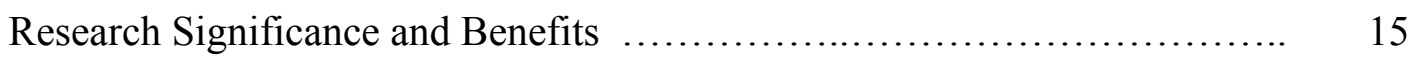

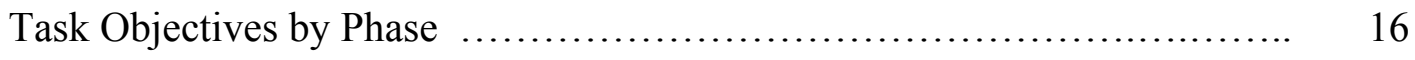

Detailed Description of Phase 2 Accomplishments ...................... 17

Mechanistic Conclusions - Damage Analysis ........................ 17

Materials Processing - Oversized Solute Addition ...................... 19

Materials Processing - Metastable Precpitates $\ldots \ldots \ldots \ldots \ldots \ldots \ldots \ldots \ldots \ldots . . \ldots 20$

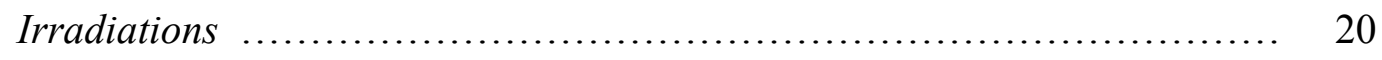

Characterizations ............................................... 22

Mechanical Behavior and Stress Corrosion Cracking ................... 40 


\title{
Novel Concepts for Damage-Resistant Alloys in Next Generation Nuclear Power Systems
}

\author{
S. M. Bruemmer and E. P. Simonen, Principal Investigators \\ Pacific Northwest National Laboratory \\ August 31, 2001
}

\section{Executive Summary}

The discovery of a damage-resistant alloy based on Hf solute additions to a low-carbon $316 \mathrm{SS}$ is the highlight of the Phase 2 research. This damage resistance is supported by characterization of radiation-induced microstructures and microchemistries along with measurements of environmental cracking. The addition of Hf to a low-carbon 316SS reduced the detrimental impact of radiation. Pt additions reduced the impact of radiation on grain boundary segregation but did not alter its effect on microstructural damage development or cracking. Because cracking susceptibility is associated with several material characteristics, separate effect experiments exploring strength effects using nonirradiated stainless steels were conducted. These crack-growth tests suggest that irradiation strength by itself can promote environmental cracking.

The concept of using oversized solutes to promote catalyzed defect recombination is a major thrust of this Nuclear Energy Research Initiative project. The successful demonstration of damage resistance in the optimized Hf-doped alloy demonstrates promise for developing damage-resistant alloys for future generation nuclear reactors. Differences between irradiation responses for Hf-doped and Pt-doped alloys suggest that the influence of the oversized elements depends on chemical reactivity in addition to solute size. Elimination of void formation to a dose of 50 dpa (during heavy-ion irradiation) is a significant improvement in material performance. Samples from these initial alloys were prepared and included in a major multi-year, neutron-irradiation program as part of collaborative research activities.

Radiation-induced strengthening is strongly correlated with susceptibility of stainless steels to IASCC. This component of damage cannot be isolated in experiments because radiation simultaneously induces changes in many alloy characteristics. Therefore, strength effects on environmental cracking susceptibility were elucidated using cold or warm work in non-irradiated stainless steels. These experiments demonstrated that strength has a systematic influence on crack-growth rate. Crack-growth rate was enhanced with increase in strength for both oxidizing and non-oxidizing environments. These results indicate that suppression of radiation-induced grain boundary segregation alone will not assure that an alloy will be resistant to cracking.

The second concept for developing damage resistant alloys is the use of metastable precipitates to stabilize the microstructure during irradiation. Three alloys have been tailored for evaluation of precipitate stability influences on damage evolution. The first alloy is a Ni-base alloy (alloy 718) that has been characterized at low neutron irradiation doses but has not been characterized at high irradiation doses. The other two alloys are Fe-base alloys (PH 17-7 and PH 17-4) that have similar precipitate structures as alloy 718 
but is more practical in nuclear structures because of the lower Ni content and hence lesser transmutation to He. During Phase 2, these alloys have been prepared and initial irradiation experiments have begun.

The successful development of next generation nuclear power systems must address and mitigate several materials degradation issues that now strongly impact existing light water reactors (LWRs) and that will limit structural materials performance at the more aggressive radiation exposures envisioned for various advanced reactor concepts.

Although previous fast reactor and fusion device programs have focused on the development of improved structural materials for their relevant conditions, there has been no comparable effort directed toward the conditions unique to LWRs. Novel, nontraditional approaches are necessary to create durable damage-resistant alloys and establish the foundation for advanced reactor designs.

\section{Project Objective}

The objective of the proposed research is to develop the scientific basis for a new class of radiation-resistant materials to meet the needs for higher performance and extended life in next generation power reactors. New structural materials are being designed to delay or eliminate the detrimental radiation-induced changes that occur in austenitic alloys, i.e., a significant increase in strength and loss in ductility ( $<10 \mathrm{dpa})$, environment-induced cracking $(<10 \mathrm{dpa})$, swelling $(<50 \mathrm{dpa})$ and embrittlement $(<100 \mathrm{dpa})$. Non-traditional approaches are employed to ameliorate the root causes of materials degradation in current LWR systems. Changes in materials design are based on mechanistic understanding of radiation damage processes and environmental degradation and the extensive experience of the principal investigators with core component response. This work is integrated with fundamental research at Pacific Northwest National Laboratory (PNNL) and with focused international projects at PNNL, General Electric Corporate Research \& Development (GECRD) and University of Michigan (UM) led by EPRI. This leveraged approach facilitates the revolutionary advances envisioned in NERI by creating a multi-faceted effort into the basic and applied science necessary to drive mechanistic understanding and promote development of next generation materials. The research strategy capitalizes on unique national laboratory, industry and university capabilities for studies of radiation damage and environmental cracking response.

\section{Project Approach}

This project will be accomplished in three phases over a three-year period as documented in this report. Accomplishments by task in Phase 2 of the project are highlighted in the description of Tasks $2 \mathrm{a}, 2 \mathrm{~b}, 2 \mathrm{c}$ and $2 \mathrm{~d}$ as part of the detailed report. In summary, novel alloys were selected on the mechanistic basis for radiation damage resistance. Although neutron irradiation of large specimens for materials characterization and mechanical property testing would be desirable, this three-year program cannot accommodate that need. In contrast, the program strategy emphasizes screening irradiation using rapid $\mathrm{Ni}^{++}$ ion irradiation for damage response. From these irradiations, proton irradiations are conducted to verify the heavy-ion response and allow selected mechanical properties and SCC behavior studies. To evaluate the effect of the irradiation damage condition on SCC, testing of deformation- or precipitation-hardened stainless steels are included in 
work scope. These high-strength, non-irradiated samples allow confirmation that matrix strength similar to that created by irradiation can promote SCC susceptibility and enable tailored microstructural changes to be evaluated. Finally, in partnership with an international program, promising alloys are being neutron irradiated for future evaluation as warranted.

\section{Phase 2 Accomplishments}

Phase 2 research is highlighted by the discovery of superior damage resistance for an optimized alloy of $316 \mathrm{SS}+\mathrm{Hf}$. The damage resistance was evidenced by no void swelling to high dpa, no radiation-induced segregation after proton irradiation and no evidence of environmental cracking after proton irradiation. This is in contrast to the clear evidence of voids, radiation-induced segregation, and cracking found in the base 316SS alloy without Hf. Samples were prepared and included in an international neutron-irradiation program to achieve doses from 5 to $20 \mathrm{dpa}$. In addition, the influence of strength on environmental cracking was quantified. The key implication is that strength alone promotes cracking without the influence of radiation-induced grain boundary segregation, irradiation-deformation microstructure, hydrogen enhancement, or martensite formation. Critical milestones where met for procuring, fabricating and irradiating alloys having damage resistance associated with metastable precipitates.

\section{Task 2a: Materials Processing}

A processing step for optimizing the $316 \mathrm{SS}+\mathrm{Hf}$ alloy was developed. The step included annealing at $1100^{\circ} \mathrm{C}$ for $30 \mathrm{~min}$ in contrast to the standard treatment of $900^{\circ} \mathrm{C}$ for $20 \mathrm{~min}$. This produced a matrix chemistry and microstructure that was subsequently demonstrated to have damage resistance. Materials were procured and heat treatments developed for evaluating damage resistance in metastable precipitated alloys.

- Various heat treatments for the 316SS+Hf alloy were evaluated to optimize the influence of Hf. The heat treatment temperature and time was increased to achieve higher levels of Hf in solution and possibly change minor element concentrations in the matrix.

- Three oversized-solute alloys were prepared for proton irradiation. The alloys included the base 316SS, the 316SS+Pt and the 316SS+Hf optimized condition.

- The oversized-solute alloys (316SS, 316SS+Pt and 316SS+Hf) were also prepared for neutron irradiation in the Bor-60 reactor.

- Alloy 718 specimens were prepared in sheet form for ion irradiation.

- Stainless alloys PH 17-7 and PH 17-4 were procured and heat treated to establish a metastable precipitation alloy. Sheet samples were extracted from the bulk material for ion irradiation. 
$\underline{\text { Task 2b: Irradiations }}$

Charged particle $\left(\mathrm{Ni}^{++}\right.$ion) irradiations were conducted to quantify the damage resistance associated with solute additions of $\mathrm{Hf}$ to the base 316SS alloy. High irradiation dose was emphasized with doses from 30 to $50 \mathrm{dpa}$. Proton irradiation was conducted to confirm the findings using charged particle irradiation for the solute addition evaluation. Also, the proton irradiations were conducted for the purpose of evaluating environmental cracking resistance and mechanical properties.

- The 316SS+Hf optimized alloy was irradiated with $\mathrm{Ni}^{++}$ions to a dose of $50 \mathrm{dpa}$ at $500^{\circ} \mathrm{C}$ to confirm the absence of swelling at high dpa.

- The 316SS+Hf alloy and the base 316SS alloy was irradiated to $30 \mathrm{dpa}$ at $500^{\circ} \mathrm{C}$ to identify the threshold for void formation in the original form of the $316 S S+H f$ alloy.

- Proton irradiation of the base 316SS, 316SS + Pt and 316SS + Hf alloys was conducted to $2.5 \mathrm{dpa}$ and $5 \mathrm{dpa}$ at $400^{\circ} \mathrm{C}$ for microstructural-microchemical characterization. The same alloys were tested using microhardness to assess irradiation strength and using constant extension rate tests for resistance to IASCC.

- Neutron irradiation of the base 316SS, 316SS+Pt and 316SS+Hf alloys was initiated in February 2001 to reach doses from 5 to 20 dpa at $330^{\circ} \mathrm{C}$ over the next 2 years.

Task 2c: Materials Characterization

Materials characterization of the irradiated alloys with solute additions underpinned the successful thesis of the proposed damage resistance. The $316 \mathrm{SS}+\mathrm{Hf}$ optimized alloy clearly exhibited damage resistance by preventing void formation and by inhibiting radiation-induced segregation at grain boundaries. Damage resistance was not evident in the other comparison alloys. In the standard heat treatment $\left(900^{\circ} \mathrm{C} / 20 \mathrm{~min}\right)$, the $\mathrm{Hf}$ doped alloy exhibited damage resistance to $10 \mathrm{dpa}$ but voids did evolve at $30 \mathrm{dpa}$. Microstructures obtained in proton-irradiated specimens to 2.5 dpa were consistent with alloying effects on microstructure obtained in Ni-ion irradiated specimens.

- Microstructural characterization of 316SS, 316SS+Pt, 316SS+Hf and 316SS+Hf optimized alloys were completed for the $\mathrm{Ni}^{++}$ion irradiations. Significantly, the $316 \mathrm{SS}+\mathrm{Hf}$ alloy showed resistance to swelling to $10 \mathrm{dpa}$ whereas the $316 \mathrm{SS}+\mathrm{Hf}$ optimized alloy showed no swelling to the highest dpa, namely $50 \mathrm{dpa}$. Documented characteristics were void, loop and precipitate sizes and number densities. Full histograms were developed for each irradiated alloy and dose.

- Microstructures were characterized for 2.5 dpa proton irradiations at $400^{\circ} \mathrm{C}$. The proton irradiation series included the 316SS, 316SS+Pt and 316SS + Hf optimized alloys. The microstructures in the proton irradiation series ranked identical to the ion irradiation series, however, the quantitative differences were greater for proton irradiation. 
- Grain boundary microchemistry was characterized in the proton irradiation series at 2.5 dpa. Compositions characterized included Fe, Cr, Ni, Si, Mo and Hf. Significantly, the 316SS + Hf optimized alloy that showed no voids also showed insignificant radiationinduced segregation.

\section{Task 2d: Mechanical Behavior and Stress Corrosion Cracking}

The dependence of IASCC on irradiation and strength was evaluated using proton irradiation and in a separate experiment using cold/warm work on nonirradiated specimens. Cracking susceptibility was demonstrated in the proton-irradiated base 316SS and the 316SS+Pt alloys. Cracking was not observed in the 316SS+Hf optimized alloy. The dependence of crack-growth rate on alloy strength in non-irradiated SSs was extensively evaluated. The strength effect was confirmed for contrasting conditions of electrochemical potential, martensite formation and hydrogen contribution.

- Constant extension rate tests in high-temperature $\left(290^{\circ} \mathrm{C}\right)$ water were performed using specimens irradiated with protons to $2.5 \mathrm{dpa}$. Stress corrosion cracking (SCC) response was characterized in the $316 \mathrm{SS}, 316 \mathrm{SS}+\mathrm{Pt}$ and $316 \mathrm{SS}+\mathrm{Hf}$ alloys. The $316 \mathrm{SS}+\mathrm{Hf}$ optimized alloy, that showed no voids, nor significant radiation-induced segregation, failed in a ductile fashion with no evidence of SCC.

- Microhardness was used to characterize the strength of specimens proton-irradiated to $2.5 \mathrm{dpa}$. The microhardness measurements did not correlate with the ranking of the alloys to cracking resistance.

- Crack-growth rates were measured in cold-worked non-irradiated specimens to explore the influence of strength on cracking. A clear correlation was developed based on strength. The effect of strength was similar for oxidizing and non-oxidizing environments. Furthermore, a temperature effect was measured but a martensite or hydrogen effect was not evident.

\section{Publications}

1. S. M. Bruemmer, "Heat-to-Heat Variability in Radiation-Induced Microstructure and Microchemistry for Commercial 300-Series Stainless Steels," Minutes of the International Collaborative Group on Environmentally Assisted Cracking, April 2000, Williamsburg, VA, Paper I13.

2. E. P. Simonen, "Transitions in Stainless Steel Radiation-Induced Microstructures from 270 to $370{ }^{\circ} \mathrm{C}$, " Minutes of the International Collaborative Group on Environmentally Assisted Cracking, April 2000, Williamsburg, VA, Paper I14.

3. J. Gan, G. Was and R. Stoller, "Modeling of Microstructure Evolution in Austenitic Stainless Steels Irradiated Under Light Water Reactor Condition," Accepted to be published in Journal of Nuclear materials, (2001). 
4. P. L. Andresen, T. M. Angeliu, W. R. Catlin, L. M. Young and R. M. Horn, "Effect of Deformation on SCC of Unsensitized Stainless Steel," Corrosion 2000, NACE, 2000, Paper 203.

5. D. J. Edwards, E. P. Simonen, F. A. Garner and S. M. Bruemmer, "Microstructural Evaluation of a Cold-Worked 316SS Baffle Bolt Irradiated in A Commercial PWR," 10th Int. Conf. Environmental Degradation of Materials in Nuclear Power Systems - Water Reactors, NACE, 2001, in press.

6. L. Fournier, J. Gan, E. P. Simonen, S. M. Bruemmer and G. S. Was, "Effect of Oversized Solute Additions on Irradiation-Assisted Stress Corrosion Cracking of Austenitic Stainless Steels," 10th Int. Conf. Environmental Degradation of Materials in Nuclear Power Systems - Water Reactors, NACE, 2001, in press.

7. J. Gan, D. J. Edwards, E. P. Simonen, G. S. Was and S. M. Bruemmer, "Microstructural Evolution and Hardening in 300-Series Stainless Steels: Comparisons Between Neutron and Proton Irradiations," 10th Int. Conf. Environmental Degradation of Materials in Nuclear Power Systems - Water Reactors, NACE, 2001, in press.

8. S. M. Bruemmer, "New Issues Concerning Radiation-Induced Material Changes and Irradiation-Assisted Stress Corrosion Cracking," Invited Paper, 10th Int. Conf. Environmental Degradation of Materials in Nuclear Power Systems - Water Reactors, NACE, 2001, in press.

9. S. M. Bruemmer, D. J. Edwards, V. Y. Gertsman and E. P. Simonen, "Grain Boundary Modification During Neutron Irradiation at Intermediate Temperatures," Invited Paper, Microstructural Processes in Irradiated Materials, Materials Research Society (MRS), 2001, p. R2.1.

10. E. P. Simonen and S. M. Bruemmer, "The Influence of Submicroscopic Vacancy Clusters During Neutron Irradiation of Stainless Steel near $300^{\circ} \mathrm{C}$," Microstructural Processes in Irradiated Materials, MRS, 2001, p. R2.5.

11. J. Gan, B. H. Sencer, L. Fournier, G. S. Was, D. J. Edwards, E. P. Simonen and S. M. Bruemmer, "Microstructural Evolution in Charged Particle Irradiated 316SS Modified to Reduce Radiation Damage," Microstructural Processes in Irradiated Materials, MRS, 2001, p. R2.6.

12. S. M. Bruemmer, D. J. Edwards, B. W. Arey and L. A. Charlot, "Microstructural, Microchemical and Hardening Evolution in LWR-Irradiated Austenitic Stainless Steel," 9th International Symposium on Environmental Degradation of Materials in Nuclear Power Systems - Water Reactors, TMS, 1999, p. 1079.

13. D. J. Edwards, E. P. Simonen and S. M. Bruemmer, "Radiation Hardening in Austenitic Stainless Steels Irradiated in LWRs," 9th International Symposium on Environmental Degradation of Materials in Nuclear Power Systems - Water Reactors, TMS, 1999, p. 1007. 
14. S. M. Bruemmer and L. E. Thomas, "Insights into Environmental Degradation Mechanisms from High-Resolution Characterization of Crack Tips," Invited Paper, Proc. Symposium on Chemistry and Electrochemistry of Corrosion and Stress Corrosion, The Minerals, Metals and Materials Society (TMS), 2001, p. 321.

15. D. J. Edwards, E. P. Simonen and S. M. Bruemmer, "Nature of the Fine-Scale Defects and Radiation Hardening in Stainless Steel Neutron-Irradiated at $550^{\circ} \mathrm{K}$," Microstructural Processes in Irradiated Materials, MRS, 2001, p. R2.7.

16. L. E. Thomas, B. H. Sencer and S. M. Bruemmer, "Radiation-Induced Phase Instabilities and Their Effects on Hardening and Solute Segregation in PrecipitationStrengthened Alloy 718," Microstructural Processes in Irradiated Materials, MRS, 2001, p. R1.5.

17. J. Gan and G. S. Was, "Microstructure Evolution in Austenitic Fe-Cr-Ni Alloys Irradiated with Protons: Comparison with Neutron-Irradiated Microstructure," Journal of Nuclear Materials, 297 (2001) 161

18. S. M. Bruemmer, "Linking Radiation-Induced Material Changes to IASCC Susceptibility," Minutes of the International Collaborative Group on Environmentally Assisted Cracking, April 2001, Kjongju, South Korea, Paper I11.

\section{Project Management}

All Phase 2 milestones were completed. Technical progress included completion of SCC testing of Phase 2 alloys to 2.5 dpa using proton irradiation. Phase 2 alloys were fabricated for heavy-ion and proton irradiation experiments. Charged particle irradiations of the Phase I alloys were completed and extended to the optimized Phase I alloy for the case of Hf addition. Demonstration of matrix strength effects on SCC growth rates was achieved. The thesis for damage modification using misfit solute atoms was confirmed by analyzing high-dose microstructures and by performing SCC tests on proton-irradiated alloys.

\section{Financial Summary}

Spending occurred at a consistent rate through the year.

Continuation of unspent funds from Phase 2 is planned to complete the strength effects on SCC study at GE-CRD. Phase I funds $(\$ 53 \mathrm{~K})$ were not spend in year 2 to allow completion of the Phase 2 crack-growth testing into year 3 .

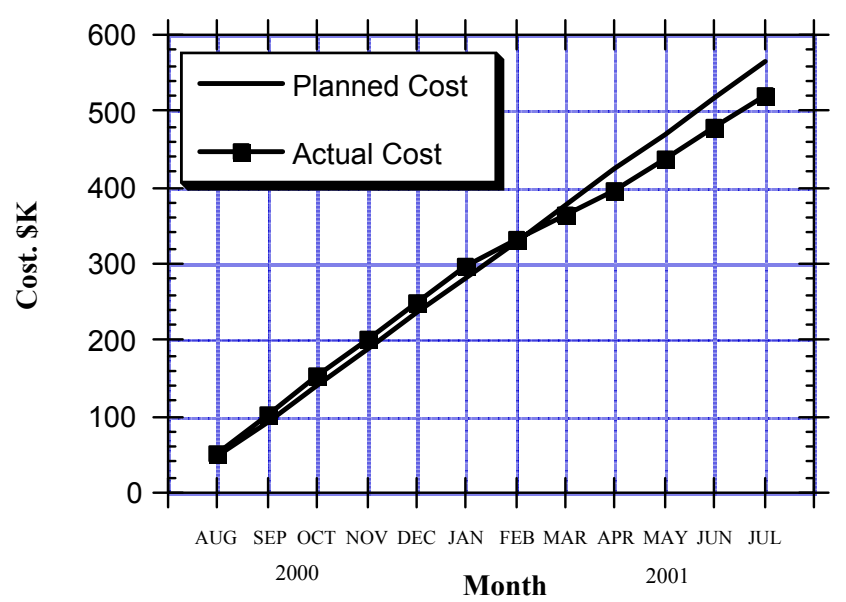




\section{Research Summary}

\section{$\underline{\text { Background }}$}

Material degradation is a primary limitation for the safe and economical operation of commercial nuclear power reactors. Traditional approaches for alloy development have emphasized minor modifications in alloys (predominantly austenitic stainless steels) that were developed for use in non-irradiation environments. As problems were discovered during service, alloy characteristics or service conditions were adjusted to provide modest improvements in performance and hopefully achieve adequate component lifetimes.

However, it is now clearly recognized that such minor traditional alterations are not sufficient to mitigate radiation-induced property degradation (loss in ductility and toughness, void swelling and embrittlement) and environmental cracking (referred to as irradiation-assisted SCC or IASCC). Therefore, unconventional metallurgical approaches and alloys outside standard stainless steels must be adopted to optimize performance in the radiation and corrosive environments of next generation nuclear reactors.

Radiation-induced degradation is driven by the displacement of atoms from their lattice sites and the subsequent creation of interstitial and vacancy defects as shown in Figure 1.

Defect recombination, migration and their annihilation at sinks promotes a wide variety of potentially detrimental material changes including dislocation loop formation that leads to extensive hardening and limited uniform ductility, segregation of alloying and impurity elements to grain boundaries and other sinks, and void swelling. These changes are inevitable in standard stainless steels during LWR irradiation and result in an increasing susceptibility to failure with core component exposure. Displacement of atoms from irradiation cannot be avoided; they are the result of fundamental Newtonian

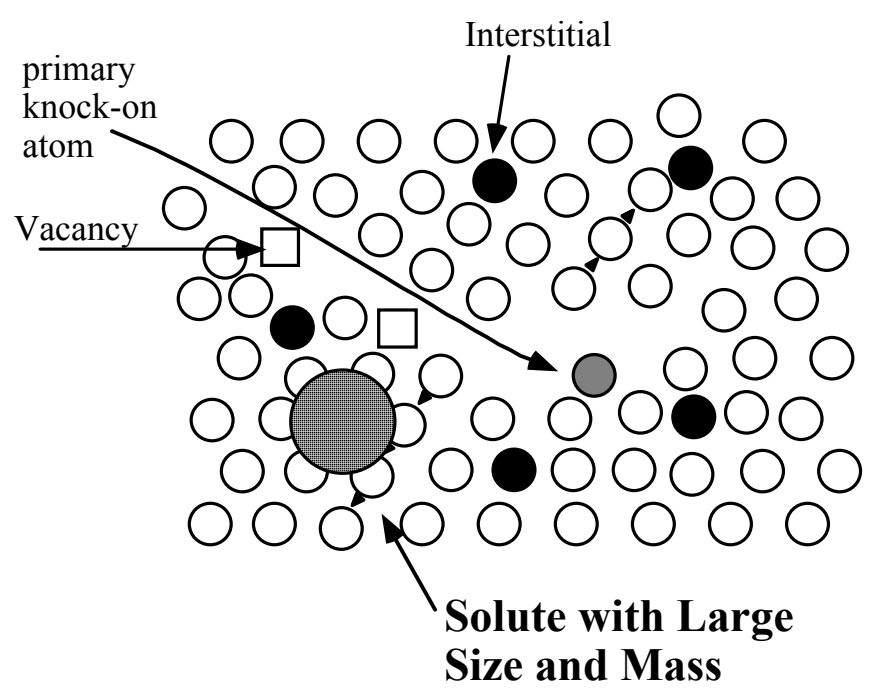

Figure 1. Schematic of the damage process for influence from a large size or large mass solute. The primary knock-on atom can be created with ions, protons or neutrons. Minor additions (3,000 appm) of massive oversized solute are being explored. Large elements in solution perturb the cascade production of defects and subsequent irradiation damage. 
mechanics. The path for aggregation of defects into detrimental microstructures can be avoided. The processes of migration and aggregation of displacement defects are illustrated in Figure 2. Atoms of large size or mass misfit and fine-scale precipitate distributions interfere with the processes of recombination, migration and aggregation.

Displacement events can be created by ion, proton or neutron particles. Heavy ions and protons have the advantage of producing damage at high rates and therefore are commonly used for fundamental studies of damage mechanisms. Neutrons have the advantage of producing damage in bulk materials and therefore have the advantage for studies of bulk properties that are relevant to assessment of structural integrity. In this research, heavy-ion irradiation is used first as a screening tool to assess damage microstructures in candidate alloys. Protons are used for additional microstructural studies and for studies of mechanical behavior and stress corrosion cracking. Specimens for neutron-induced damage are included in a collaborative research program using the Boris reactor in Russia. The neutron-irradiated samples will not be examined under this NERI program. Damage from ions, protons and neutrons can be related using a compensation of higher temperature for higher rate processes. The interdependence of damage rate, temperature and particle type is shown in Figure 3.

The development of radiation damage microstructures has two primary effects on components: (1) swelling and (2) mechanical behavior. Swelling is detrimental because
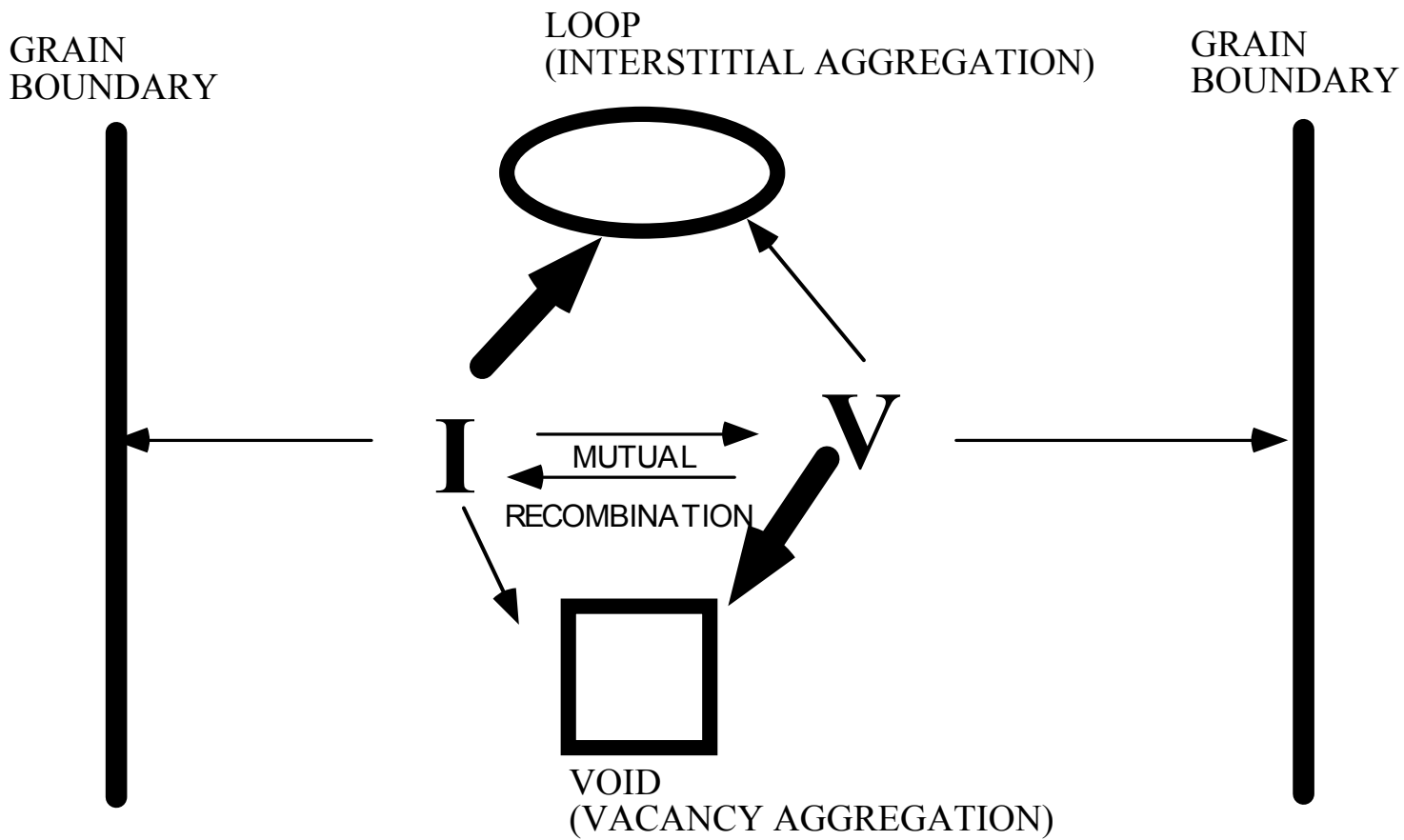

Figure 2. The fundamental products of displacement damage are interstitials (I) and vacancies(V). These point defects migrate and collect in components of radiation damage. Interstitials collect preferentially in interstitial loops and the remaining supersaturation of vacancies collect in voids. Solute atoms of large size or mass misfit and preciptiates disturb the migration and aggregation of these point defects and therefore damage evolution is optimized. Damage can be induced using ions, protons or neutrons (Task $2 b$ ) and can be characterized using transmission electron microscopy (Task 2c). The damage effect on mechanical properties and stress corrosion cracking are evaluated in Task $2 \mathrm{~d}$. 


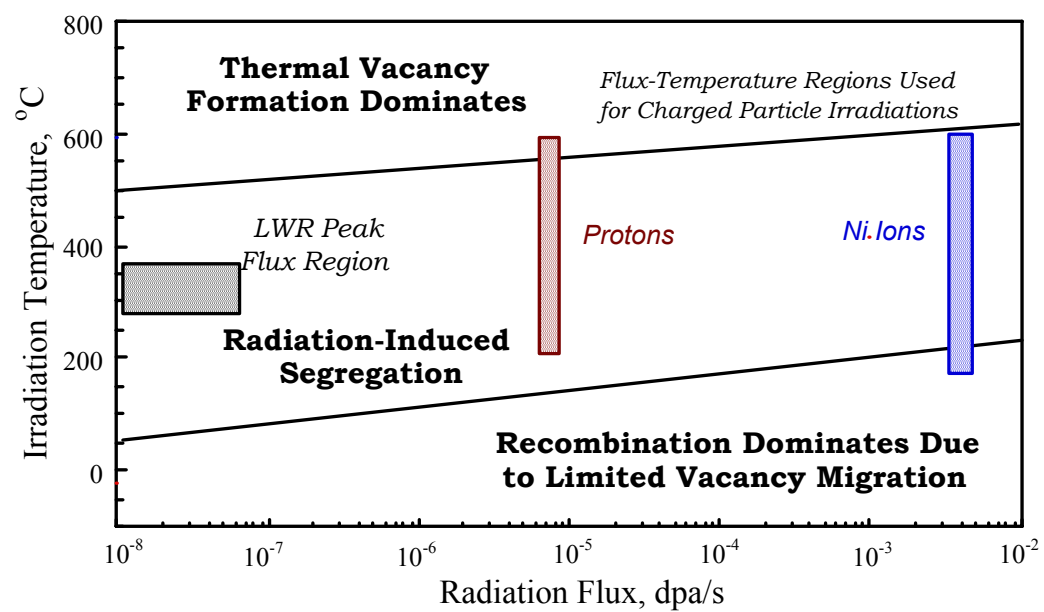

Figure 3. Increasing the rate of damage requires using a higher temperature to obtain equivalent damage microstructures. The lower temperature range is limited by mutual recombination and the upper temperature range is limited by the energy for vacancy formation. Equivalent ranges for neutrons, protons and ions are shown.

the component dimensions change during service which affect stresses and core component dimensional tolerances. A primary concern in the present research is the affect on mechanical behavior and IGSCC. The effect of displacement damage on interstitial loop development, and on the increase in yield strength, for LWR-irradiated components has been documented. The measured increase in tensile yield strength is shown in Figure 4. A four-fold increase in yield strength occurs over the first few dpa of

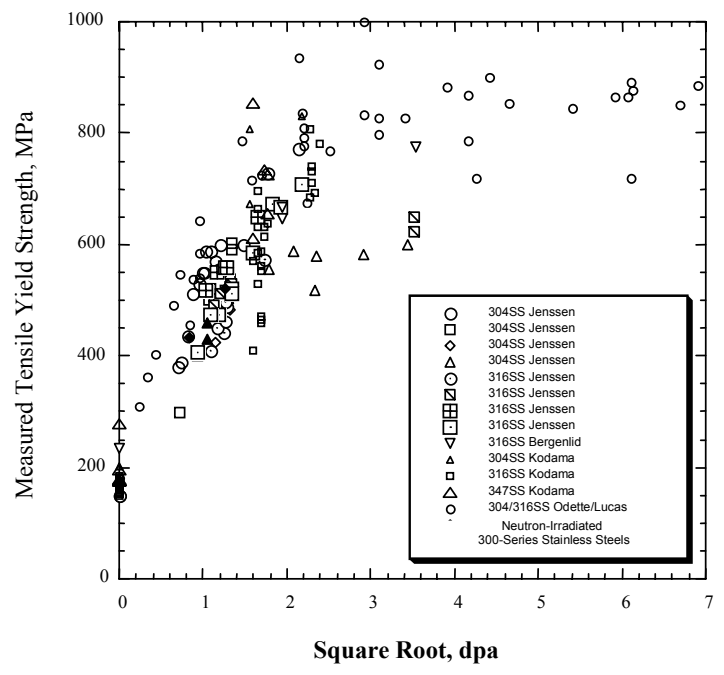

Figure 4. Irradiation Dose Effects on Measured Tensile Yield Strength for Several 300-Series Stainless Steels reported in the literature near $288^{\circ} \mathrm{C}$. Microstructures for several of these alloys were characterized at PNNL. 
irradiation. The effect of this large increase in yield strength on IGSCC is a critical issue examined in this research.

The critical links between damage processes, materials characterization and property measurements are highlighted in Figure 5. Although the primary components of irradiation damage (vacancies and interstitials) are simple, their aggregation into the microstructure and influence on deformation, void swelling and fracture are complex processes requiring a complementary mix of experiments being conducted on this NERI program.

The above radiation damage mechanisms affect lifetime for components exposed to high irradiation doses as shown in Figure 6. Recent work has enabled many aspects of IASCC phenomenology to be explained (and predicted) based on the experience with IGSCC of non-irradiated stainless steel in BWR water environments. This continuum approach has successfully accounted for radiation effects on water chemistry and its influence on electrochemical corrosion potential. However, the specific radiation-induced microstructural and microchemical changes that promote IASCC susceptibility are largely unknown. Well-controlled IASCC data from properly irradiated, and properly characterized, materials is sorely lacking due to the experimental difficulties and financial limitations related to working with highly activated materials. The paramount need to understand and mitigate IASCC led to the formation of an internationally funded, Cooperative IASCC research project of which PNNL is a participant. Many of the important metallurgical, mechanical and environmental aspects that are believed to play a role in the cracking process are illustrated in Figure 5. Since only persistent material changes are required for IASCC to occur, in-core processes such as radiation creep and radiolysis influence cracking, but are not controlling mechanisms. The current understanding of persistent material changes (dose affects) that are produced in stainless alloys during LWR irradiation is elucidated based on the fundamentals of radiation damage from experimental measurements.

\section{$\underline{\text { Research Approach }}$}

The response of alloys to irradiation has been evaluated using a variety of irradiation experiments using neutrons, electrons, protons and heavy ions. Each irradiation technique possesses both advantages and disadvantages. Neutron irradiation is the preferred choice based on providing the practical environment of engineering interest. Conversely, neutron irradiation has the disadvantage of requiring expensive resources and many years for materials studies. PNNL has an extensive history in the conduct and interpretation of neutron and charged-particle experiments from mechanistic and alloy development efforts for fast-reactor and fusion-energy programs.

A productive approach for obtaining screening results has been to use charged particle irradiations for establishing the physical basis for phenomenological interpretation and mechanism development. Research conducted over the last ten years at PNNL has demonstrated that quantitative comparisons between $\mathrm{Ni}^{++}$ion and LWR neutron irradiations can be made for radiation-induced microstructural (defect clusters, dislocation loops and voids) and microchemical (grain boundary segregation) evolution. 


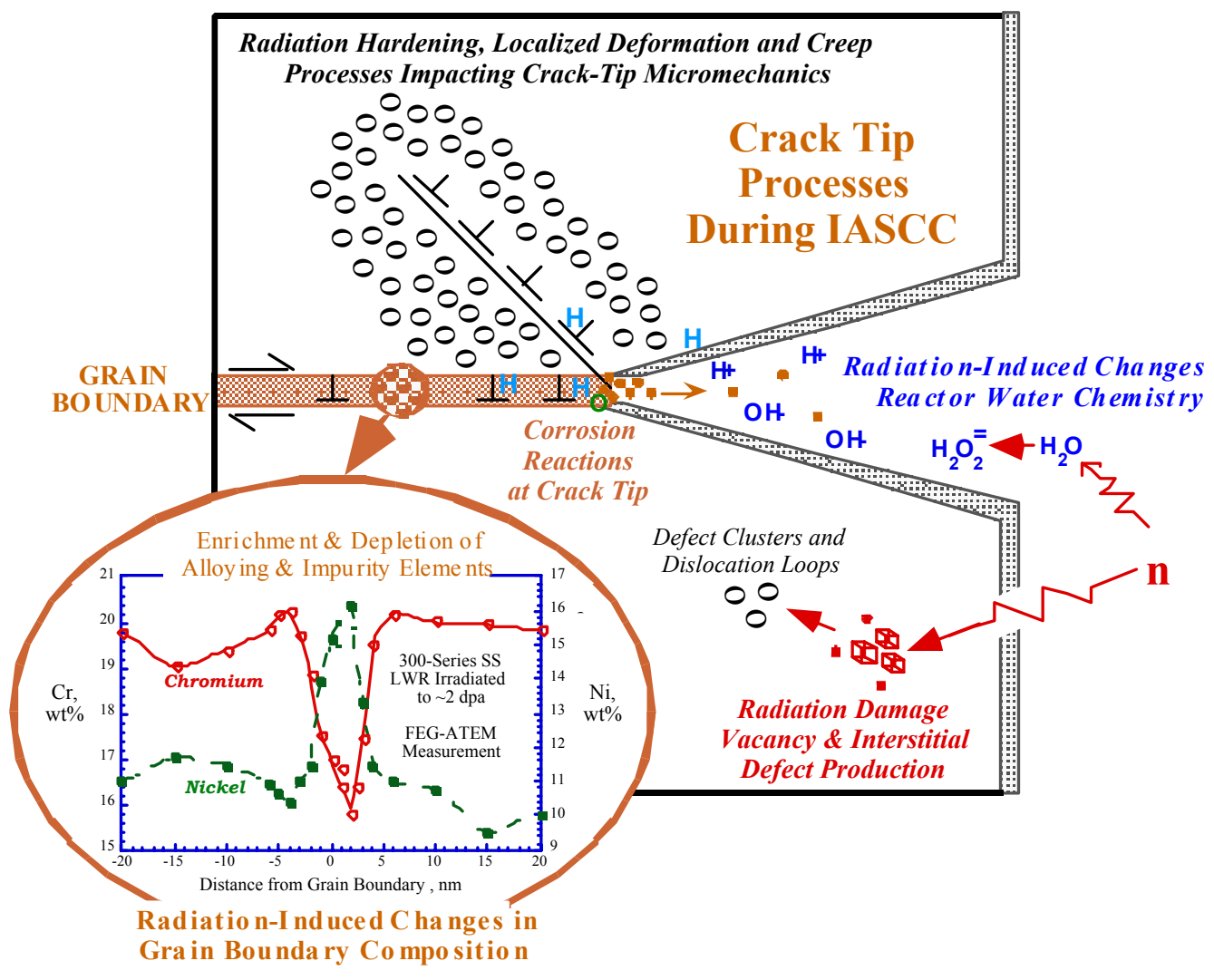

Figure 5. Schematic illustrating mechanistic issues believed to influence crack advance during IASCC. Understanding is advanced through alloy design (Task 2a), irradiation experiments (ion, protons and neutrons in Task 2b), microstructural and microchemical characterization (Task 2c), and measurements of mechanical and stress corrosion cracking properties (Task 2d). Interstitial aggregation results in loops that affect strength which in turn affects SCC. Concurrent void production (not shown in the schematic) does not affect IASCC but does affect dimensional stability and component lifetime.

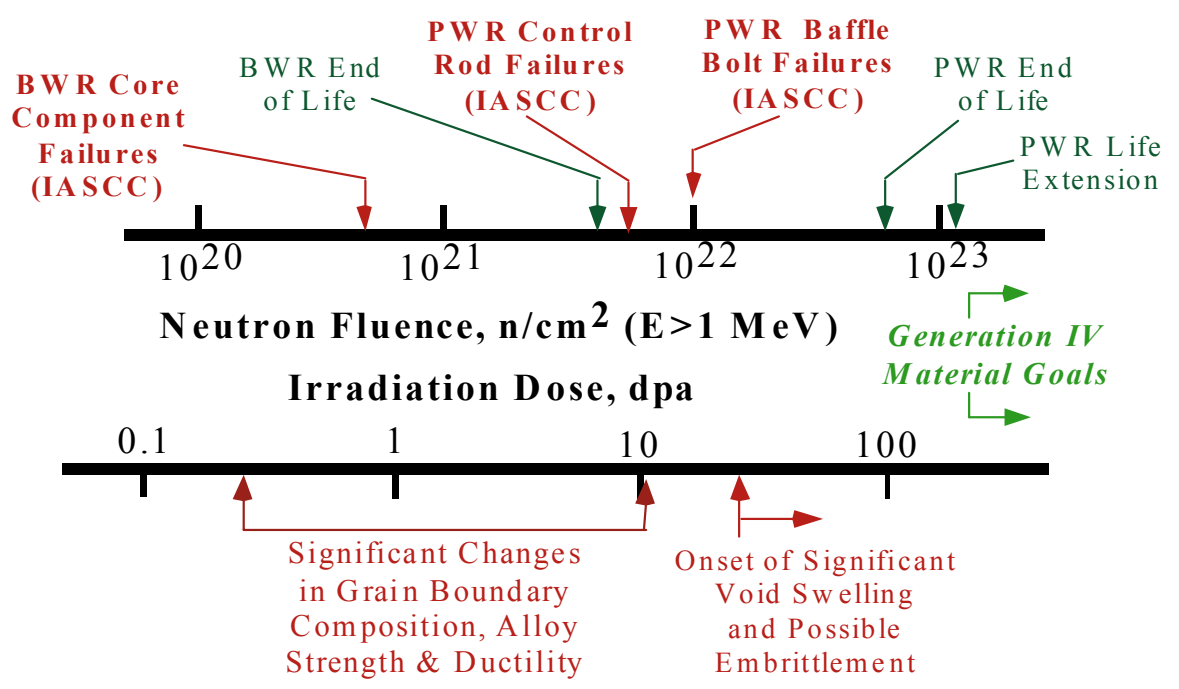

Figure 6. Neutron fluence effects on alloy characteristics and IASCC susceptibility of Type 304SS in LWR environments. Dose effects on mechanical behavior and swelling are also shown. These failure modes are elucidated in Task $2 \mathrm{~d}$. 
In addition, localized deformation and hardening behavior has been effectively investigated. Within this irradiation strategy, neutron irradiations are used to confirm and calibrate models for mechanistic interpretation and engineering applications.

Proton irradiation techniques have been developed in parallel with heavy-ion irradiation techniques. Similar advantages and disadvantages occur for both. Proton penetration depths are greater than for heavy ions $(40 \mu \mathrm{m}$ vs. $1 \mu \mathrm{m})$ making protons a preferred technique for observing "bulk" irradiation effects and mechanical property behavior. Proton PKA spectra are softer than heavy ions and neutrons but none-the-less many experimental correlations have indicated the usefulness of proton irradiation for simulating neutron irradiation effects. Recent work at UM has demonstrated that radiation microstructures (dislocation loops and voids), microchemistries (grain boundary segregation), hardening and IASCC susceptibility can be produced by proton irradiation (at $360^{\circ} \mathrm{C}$ ) in 300 -series stainless steels in a nearly identical fashion as for LWR neutrons (at $280^{\circ} \mathrm{C}$ ).

Standard mechanical property and SCC tests cannot be performed in ion-irradiated specimens because of the limited depth range of ions. Therefore, a strategy has been adopted based on using thermo-mechanical heat treatments of non-irradiated alloys to produce similar microchemistries and mechanical properties as expected in irradiated alloys. A continuum in SCC behavior has been demonstrated using irradiated and nonirradiated specimens of the same alloy type. In Phase 2 cold working on non-irradiated 300 series stainless steels is evaluated to demonstrate if loop formation and irradiation strengthening can promote enhanced crack-growth rates without the need for irradiationinduced microchemical changes.

\section{$\underline{\text { Research Significance and Benefits }}$}

The present research has the potential to eliminate one of the most significant economic and safety issues facing current and future nuclear power systems. This work integrates fundamental and applied science resources to design advanced core component structural materials with the required resistance to radiation and environmental degradation mechanisms. Thus, the research benefits a wide range of areas from fundamental science to applied alloy development. The research strategy and the combination of national laboratory, industry and university resources enables important NERI objectives to be achieved:

1) Advanced materials concepts are being developed and scientific breakthroughs facilitated to overcome a principal obstacle facing nuclear fission reactors. The focus on next generation LWR concepts will promote relatively near-term (within 10 years) benefits for the safe and economical operation of commercial nuclear power. This is essential considering the current status of the nuclear power industry worldwide.

(2) The effective integration of national laboratory (PNNL), industry (GECRD and Framatome) and university (UM) team members focuses their scientific research and development infrastructures on nuclear energy issues and fosters a leveraged approach to address basic and mission-oriented research. Industry partners and collaborators ensures that radiation material science breakthroughs are effectively 
transferred to advance the state of nuclear technology. International cooperation and U.S. leadership in the research is ensured by the collaborative experimental activities as part of two separate multi-national projects led by EPRI. Principal investigators play an important role in the oversight of these projects and foster continuous interactions to transfer novel materials concepts into engineering application.

(3) The unique research team and shared activities among national laboratory, industry and university promotes and maintains nuclear science and engineering to meet future technical challenges. The relationship among participants is one of the strengths of this proposal and fosters the development of new radiation materials science expertise through research activities by university students (UM) and junior staff (PNNL and GECRD) at laboratories.

(4) The objective of this research is to help solve critical materials degradation problems for current and next generation LWRs. The development of new damageresistant alloys will allow advanced power reactors to be designed and operated for improved performance, efficiency, reliability and economics.

\section{Task Objectives by Phase}

The success of this program is achieved in three phases. In Phase 1, tailored alloys were evaluation based on the concept of solute misfit influences on damage evolution at high doses. The progress was enabled through upgrades of irradiation facilities and methods for specimen characterization. Ion irradiation provided a rapid screening technique to assess damage to be followed by proton irradiation that allows property evaluations. Simultaneously, thermo-mechanical treatments were used to fabricate specimens for measurement of crack-growth rates in for alloys having properties similar to irradiated properties. In Phase 2 , property evaluation of alloys studied in Phase 1 were conducted and experiments using tailored precipitate microstructures that show superior retention of the desirable pre-irradiation microstructures and properties were initiated. In Phase 3 , concluding studies of the two alloy types, i.e., with solute additions or metastable precipitates, will be finalized and mechanistic models will be established to rationalize the beneficial microstructures observed in the tailored alloys.

Phase 1:

Phase 1 has been completed and objectives achieved. Materials available from prior or on-going research efforts at PNNL and GECRD were obtained and samples were prepared for initial charged particle irradiation. In addition, capital improvements to accelerators to allow higher beam currents and dose rates at UM and to provide a new high-flux, high-temperature irradiation chamber at PNNL were completed. Task 1 alloys containing Pt additions or Hf additions were cast by GECRD and processed at PNNL to prepare samples for heavy-ion and proton irradiations. $\mathrm{Ni}^{++}$ion screening experiments were completed at PNNL to assess the influence of these solutes on radiation-induced microstructural and microchemical evolution. Proton irradiation and material characterizations at UM were initiated using the same alloys used at PNNL. Direct comparison were made (in Phase 2) between the UM results and existing PNNL work on these alloys. High strength levels matching typical irradiated values were produced in the base $316 \mathrm{~L} \mathrm{SS}$. Testing at GECRD was conducted on a commercial 316L SS to quantify 
strength effects on SCC so that the influence of the misfit solute additions can be documented in Phases 2 and 3. This material is closely integrated into collaborative industrial research efforts on SCC behavior in LWR core component materials.

Phase 2:

Heavy-ion irradiation screening experiments were completed on Task 1 alloys and specific alloys were included in the proton-irradiation and SCC crack-growth test matrices. The most promising alloys were entered into the neutron-irradiation experiments as part of the collaborative EPRI-led, international research programs.

Further work at PNNL was conducted on the Task 1 approach by altering composition to optimize defect recombination. Research at UM (radiation damage and SCC resistance of irradiated microstructures) and GECRD (SCC resistance of thermo-mechanically processed alloys to simulate radiation-hardened microstructures) were focused on the most promising alloys based on the screening tests. Examinations of alternative Task 2 alloys with optimized metastable second-phase distributions were started at PNNL to indicate dynamic radiation phase stability.

Phase 3:

PNNL heavy-ion irradiation experiments and materials characterizations will be completed by mid-year on the optimized Task 1 and Task 2 alloys. Dose-dependent microstructural and microchemical evolution will be documented out to very high doses. Mechanistic underpinning for these two approaches will be established and a combination of molecular dynamics and rate theory modeling will be used to investigate specific effects during cascade formation and healing. UM proton irradiations and testing will be completed on the optimized alloys to confirm low-dose radiation-induced material changes and effects on IASCC resistance. Specific alloys will be selected for neutron irradiations to confirm improved damage resistance of optimized alloys and mechanistic aspects controlling this behavior. Crack-growth experiments at GECRD will focus on second-phase microstructural effects in the Task 2 alloys. Thermo-mechanical treatments will be used to simulate radiation-induced precipitate microstructures and strength levels to evaluate resistance to SCC.

\section{Detailed Description of Phase 2 Accomplishments}

This research has established that oversized elements affect radiation-induced microstructure and microchemistry. The comparison of behavior in alloys containing $\mathrm{Pt}$ addition and Hf addition reveals mechanistic insights for development of damage resistant alloys. The experimental findings reveal that solute size, reactivity and distribution are critical characteristics affecting radiation damage. Key findings include (1) reduction in damage evolution for Hf addition but not for Pt addition and (2) reduction in radiation-induced segregation (RIS) for both $\mathrm{Pt}$ and Hf additions. Consistent results were found for both $\mathrm{Ni}^{++}$ion irradiation and proton irradiation. The impact of developed microstructures on component properties is also addressed.

\section{Mechanistic Conclusions - Damage Analysis}

Fundamentally, radiation effects are dominated by the production, recombination and annihilation of vacancies and interstitials. The mechanistic influence of oversized solute 
is understood in terms of in-cascade recombination, intra-cascade recombination and partitioning of defects into accumulating microstructure. The roles of these mechanisms are elucidated in the present comparison experiments. The following discussion describes mechanistic conclusions relating oversized solute effects.

In-cascade recombination is not significant because the radiation response using heavy $\mathrm{Ni}^{++}$ions was observed to be similar to that for light protons. $\mathrm{Ni}^{++}$ions produce point defects mainly in large cascades whereas protons produce damage mainly in isolated pairs, which is a consequence of the bombarding particle mass. If in-cascade recombination is dominant then the damage induced with $\mathrm{Ni}^{++}$would have been much less than that induced with protons. Furthermore, RIS modeling indicates that the necessary reduction in damage efficiencies must be two orders of magnitude less for the doped alloys compared to the base alloy to explain measured segregation results. The assumed low damage efficiency cannot be justified based on independent experiments.

Alternatively, intra-cascade recombination is significant as implied by the large reduction in RIS for alloys containing oversized elements compared to the base-alloy. RIS is a process that does not depend on partitioning of vacancies and interstitials into persistent damage microstructure but rather depends on the total flow of defects to sinks such as grain boundaries. The absence of significant RIS for the doped alloys implies that the number of vacancies and interstitials arriving at grain boundaries is strongly reduced by the solute additions.

Preliminary rate theory calculations of defect production, recombination and annihilation indicate that binding between oversized solute and vacancies causes reduction in RIS. Model calculations show that the reduced RIS cannot be attributed to recombination cause by slow vacancy mobility. Furthermore, the existence of precipitates in the Hfdoped alloy does not impact intra-cascade recombination. The precipitate sizes and number densities are not high enough to compete with alternative mechanisms. Also, the similar RIS behavior for the Hf-doped alloy and the Pt-doped alloy indicates that Hf precipitates are not important for control of RIS.

Remarkably, specific solute effects on RIS do not parallel effects on microstructural evolution. This implies that solute size alone does not control production of radiation microstructure. Based on size, Pt is expected to have an intermediate effect on damage when compared to the base 316SS and the Hf-doped alloy. The influence of Pt addition (10\% misfit) on microstructural evolution was not significant in contrast to the dominant influence of Hf addition ( $26 \%$ misfit). Hf-doped alloys developed smaller interstitial loops and lack of voids when compared to the Pt-doped alloy and the base 316SS alloy. These observations support a mechanism for Hf influence related to suppression of loop growth and suppression of void nucleation. The extreme size misfit for $\mathrm{Hf}$ and the reactive chemical nature of Hf likely impart the damage resistance observed in this study.

The mechanistic assessment of these experimental results makes clear the promise that metallurgical processes can be developed to eliminate or retard detrimental microstructures that impact components in the next generation nuclear reactors. The processing, irradiation, characterization and property measurements that support this conclusion are detailed in the following sections. 
Materials Processing - Oversized Solute Addition

Special heats of the research alloys were melted at GECRD. The baseline alloy was a composition representative of commercial 316SS but of high purity. Doping with $\mathrm{Hf}$ and Pt was achieved by adding 0.3 at $\%$ of the desired solute. Atomic mass and atomic size were the distinctive solute properties of interest. A comparison of size and mass is shown in Figure 7.

Both $\mathrm{Hf}$ and $\mathrm{Pt}$ have excessive mass in comparison to $\mathrm{Fe}, \mathrm{Cr}$ and $\mathrm{Ni}$. The size misfits are also large with Hf having a greater misfit. The alloys were all arc melted multiple times, and the convective stirring was very high, as was the cooling rate to ensure good homogeneity. The ingot was approximately $75 \mathrm{~mm}$ in diameter and $18-\mathrm{mm}$ thick as melted. The compositions of the three alloys are shown in Table 1.

For ion irradiation, pieces from the melted ingot were sliced off for thermo-mechanical processing. A solution anneal was performed at $1200^{\circ} \mathrm{C}$ for 1 hour prior to $70 \%$ cold working. Cold working was followed by a $900^{\circ} \mathrm{C}$ anneal for 20 minutes to obtain a grain size of about $10 \mu \mathrm{m}$. The optimum time and temperature was determined from a systematic study of annealing effects on a well-defined grain distribution of a small size. The observation of Hf-rich precipitates in the 316SS+Hf alloy prompted a second series of heat treatments to redistribute solute in solution. A heat treatment at $1100^{\circ} \mathrm{C}$ was

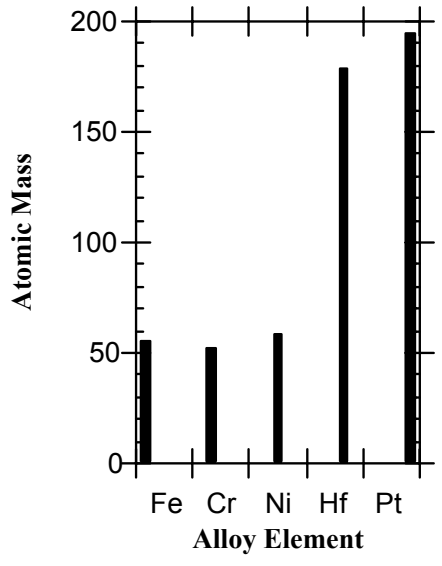

(a)

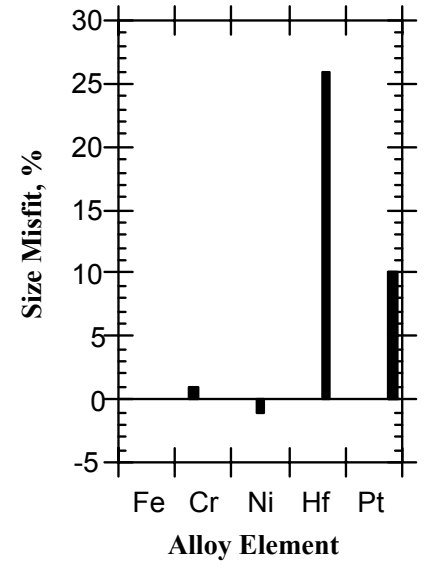

(b)

Figure 7. Comparison of mass and size of elements in the project alloys. Hf and Pt have a large misfit in both mass and size.

Table 1. Oversized Solute Alloy Compositions in wt. \%

$\begin{array}{lllllllll}\text { Alloy } & \mathrm{Cr} & \mathrm{Ni} & \mathrm{Mn} & \mathrm{Mo} & \mathrm{Si} & \mathrm{C} & \text { Other } & \text { Treatment } \\ & & & & & & & & \\ \text { 316L SS } & 17.3 & 14 & 1.2 & 2.2 & 0.08 & 0.020 & \text { Base } 316 \mathrm{~L} & 900^{\circ} \mathrm{C} / 20 \mathrm{~min} \\ \text { 316L+Pt } & 17.3 & 14 & 1.2 & 2.2 & 0.08 & 0.020 & +1.0 \% \mathrm{Pt} & 900^{\circ} \mathrm{C} / 20 \mathrm{~min} \\ \text { 316L+Hf } & 17.3 & 14 & 1.2 & 2.2 & 0.08 & 0.020 & +0.915 \% \mathrm{Hf}^{*} & 900^{\circ} \mathrm{C} / 20 \mathrm{~min} \\ \text { 316L+Hf mod. } & 17.3 & 14 & 1.2 & 2.2 & 0.08 & 0.020 & +0.915 \% \mathrm{Hf}^{*} & 1100^{\circ} \mathrm{C} / 30 \mathrm{~min}\end{array}$

* Hf at same atomic conc. same as Pt (0.3 at \%) 
chosen based on a balance between grain size and precipitation. Prior to ion irradiation the samples were wet-polished with a $\mathrm{SiC}$ paper to 600 grit, diamond abrasive file to 3 $\mu \mathrm{m}$ and a final polish of $0.3-\mu \mathrm{m}$ alumina.

Similarly for proton irradiation, separate pieces from the melted ingot were sliced off for thermo-mechanical processing. Before irradiation, specimens were polished to a 400 -grit $\mathrm{SiC}$ paper finish and then electropolished in a $60 \%$ phosphoric acid and $40 \%$ sulfuric acid solution at $45{ }^{\circ} \mathrm{C}$ for 3 minutes at $30 \mathrm{~V}$.

\section{Materials Processing - Metastable Precipitates}

The Ni-base alloy with metastable precipitates (alloy 718) was obtained from a prior neutron irradiation study. Prior to irradiation the alloy was processed according to the following treatment: $954^{\circ} \mathrm{C} / 1 \mathrm{~h}+718^{\circ} \mathrm{C} / 8 \mathrm{~h}+$ furnace cool to $621^{\circ} \mathrm{C} / 8 \mathrm{~h}$. Tubing samples were wet-polished with a $\mathrm{SiC}$ paper to 600 grit, diamond abrasive file to $3 \mu \mathrm{m}$ and a final polish of $0.3-\mu \mathrm{m}$ alumina. The alloy composition is given in Table 2.

The Fe-base samples (PH 17-7 and PH17-4) were obtained as solution-annealed plate material. Material was processed according to the following treatment: $500^{\circ} \mathrm{C} / 1 \mathrm{~h}+$ $550^{\circ} \mathrm{C} / 0.5 \mathrm{~h}+$ air cool. Slices of each alloy were extracted and subsequently polished in the conventional manner. The alloy compositions are given in Tables 3 and 4.

\section{Irradiations}

The strategy for performing irradiation is to first investigate the irradiation response using $\mathrm{Ni}$ ions. Based on these findings, proton irradiation conditions are identified. Lastly, alloys in this program are being included in neutron irradiation experiments for possible future characterization activities. Successful irradiation of all Phase 2 alloys was completed for radiation damage characterization in Task $2 \mathrm{c}$.

\section{$\mathrm{Ni}^{++}$Ion Irradiation}

$\mathrm{Ni}^{++}$ion irradiation is achieved using a $3.4 \mathrm{MeV}$ ion accelerator at PNNL's

Environmental and Molecular Sciences Laboratory. This NERI research program is the first to use this accelerator for controlled high-temperature displacement damage experiments. Ni ions are produced from solid Ni sources using $\mathrm{Cs}^{+}$sputtering in the

Table 2. Alloy 718 Composition in wt. \%

\begin{tabular}{|l|l|l|l|l|l|l|l|l|l|l|l|l|l|l|l|}
\hline $\mathrm{C}$ & $\mathrm{Fe}$ & $\mathrm{Ni}$ & $\mathrm{Cr}$ & $\mathrm{Mn}$ & $\mathrm{Mo}$ & $\mathrm{Nb}$ & $\mathrm{Ti}$ & $\mathrm{Al}$ & $\mathrm{Si}$ & $\mathrm{N}$ & $\mathrm{S}$ & $\mathrm{P}$ & $\mathrm{Cu}$ & $\mathrm{B}$ & $\mathrm{Co}$ \\
\hline .06 & 19.2 & 52.0 & 18.1 & 0.2 & 3.1 & 5.3 & 1.0 & 0.6 & 0.23 & 0.007 & 0.001 & 0.015 & 0.10 & 0.006 & 0.24 \\
\hline
\end{tabular}

Table 3. PH 17-7 Composition in wt. \%

\begin{tabular}{|l|l|l|l|l|l|l|l|l|l|l|l|l|}
\hline Fe & $\mathrm{C}$ & $\mathrm{Mn}$ & $\mathrm{P}$ & $\mathrm{S}$ & $\mathrm{Si}$ & $\mathrm{Ni}$ & $\mathrm{Cr}$ & $\mathrm{Mo}$ & $\mathrm{Co}$ & $\mathrm{Cu}$ & $\mathrm{N}$ & $\mathrm{Al}$ \\
\hline balance & .073 & .84 & .023 & .0003 & .40 & 6.97 & 16.94 & .20 & .074 & .20 & .037 & 1.082 \\
\hline
\end{tabular}

Table 4. PH 17-4 Composition in wt. \%

\begin{tabular}{|l|l|l|l|l|l|l|l|l|l|l|l|}
\hline $\mathrm{Fe}$ & $\mathrm{C}$ & $\mathrm{Mn}$ & $\mathrm{P}$ & $\mathrm{S}$ & $\mathrm{Si}$ & $\mathrm{Ni}$ & $\mathrm{Cr}$ & $\mathrm{Mo}$ & $\mathrm{Cu}$ & $\mathrm{Nb}$ & $\mathrm{Ta}$ \\
\hline balance & .040 & .63 & .028 & .014 & .48 & 4.31 & 15.33 & .19 & 3.21 & .28 & .005 \\
\hline
\end{tabular}


SNICS II (Source of Negative Ions by Cesium Sputtering) ion source. The negative Ni ions are injected into the accelerator by an injector magnet at the low energy beam line. The low energy beam line is equipped with several other components that include an electrostatic $x-y$ steerer to steer the beam, a beam profile monitor to measure the profile of the ion beam, a Faraday cup for current measurements, and an einzel lens for focusing.

The accelerator is a National Electrostatics Corporation (NEC) model 9SDH-2, 3.4 MV tandem electrostatic accelerator equipped with two Pelletron charging chains capable of carrying $300 \mathrm{~mA}$ charging current to the terminal. The accelerated ions can be focused through the high-energy beam line using a magnetic quadrupole and a y-axis electrostatic steerer which are attached to the high-energy beam line.

The beam line is equipped with a single slit followed by a matched set of two slits to control the divergence of the ion beam; a quadrupole magnet at the focal position of the switching magnet to enhance the focusing capability of the beam line; $x$ and $y$ electromagnetic steerers; a Faraday cup for current measurement; and a beam profile monitor to monitor the beam profile. Differential pumping is included in the beam line and apertures so that the end station can be kept in the low $10^{-10}$ torr pressure range. Turbo pumps are attached to all beam lines and ion sources. Typical base pressure in the low energy beam line is $1 \times 10^{-8}$ torr to $2 \times 10^{-8}$ torr, and the mid-to-high $10^{-9}$ torr range in the high energy beam lines. When the accelerator is in operation, typical pressures in the high energy beam lines are in the low-to-mid $10^{-8}$ torr range.

Specifically in this NERI program, $5 \mathrm{MeV} \mathrm{Ni}^{++}$ions are used at a current density of $90 \mathrm{nA}$ on an irradiated area of $7 \times 7 \mathrm{~mm}^{2}$. Using the TRIM 2000 code, the calculated displacement rate is $4.73 \times 10^{-4} \mathrm{dpa} / \mathrm{s}$ at a depth of $0.5 \mu \mathrm{m}$. The calculated damage depth profile is shown in Figure 8. At this rate, 1 dpa is obtained in 35 minutes. The beam current is increased for high dose irradiation, i.e., $50 \mathrm{dpa}$. The dpa calculations are based on the full cascade detailed calculation assuming a displacement energy of $40 \mathrm{eV}$ and an alloy composition for $316 \mathrm{SS}$.

The sample temperature is monitored using a thermocouple and an optical pyrometer. Calibration experiments were performed to ensure a temperature within $10^{\circ} \mathrm{C}$ of the planned irradiation. The beam profile is monitored using slits that indicate the symmetry of the beam and the assurance of a constant beam current.

\section{Proton Irradiation}

Proton irradiation is being conducted at the UM Ion Beam Laboratory using $3.2 \mathrm{MeV}$ protons at a standard current yielding a damage rate of $7 \times 10^{-6} \mathrm{dpa} / \mathrm{s}$. The high dose requirements of this NERI program has required upgrading the source current in the facility during Phase 1 of the project.

The new ion source from National Electrostatics Inc. has successfully produced in excess of $300 \mu \mathrm{A}$ of $\mathrm{p}^{+}$in the low energy section of the accelerator. Protons have also been accelerated at $150 \mu \mathrm{A}$ of $\mathrm{p}^{+}$to $3.2 \mathrm{MeV}$. Thus far, operation has been successful with about $45 \mu \mathrm{A}$ at the high-energy end. 


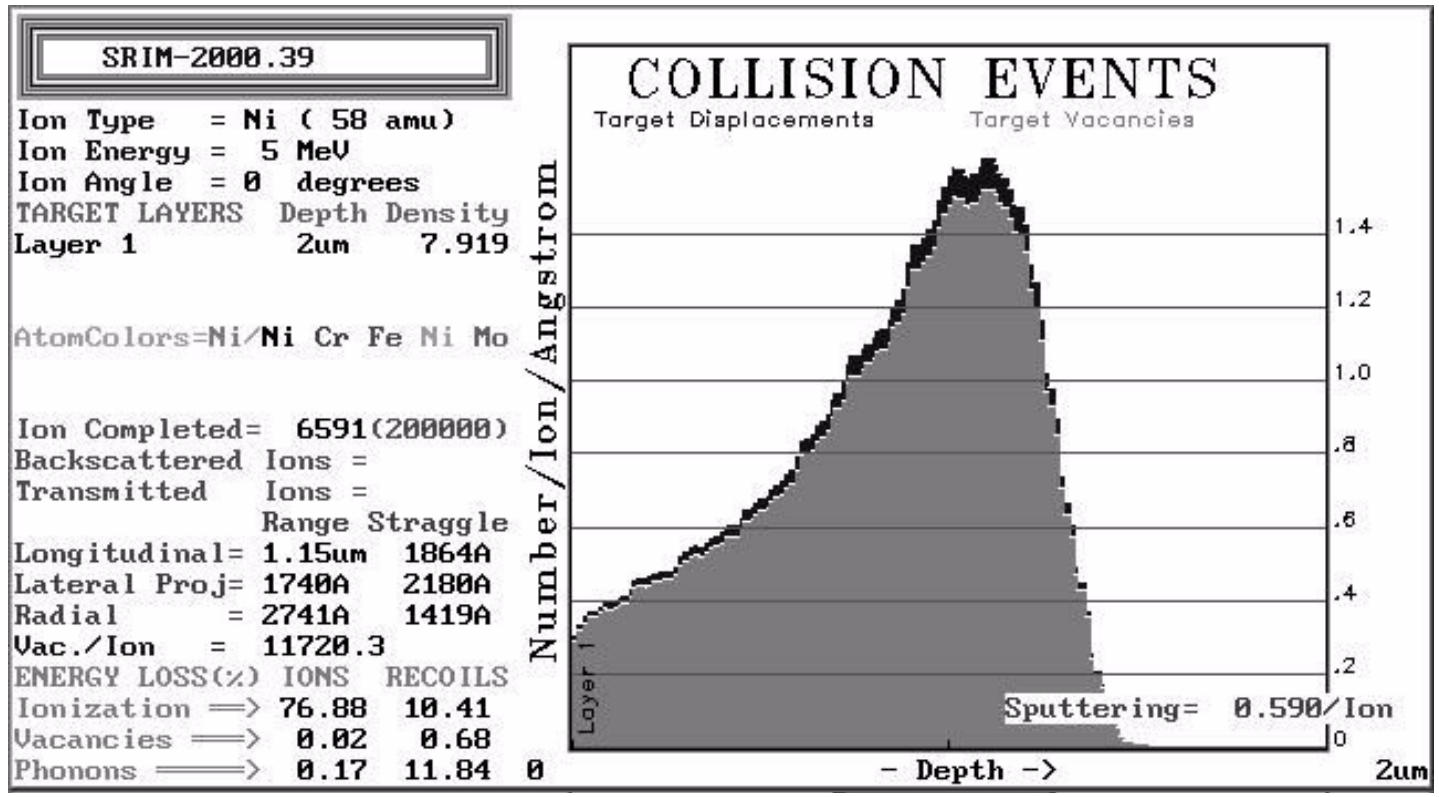

Figure 8. The depth distribution of damage based on the TRIM 2000 code. The ion range is $1.15 \mu \mathrm{m}$. In this study, microstructures were examined at a depth of $0.5 \mu \mathrm{m}$.

The irradiation temperature is controlled within $10^{\circ} \mathrm{C}$ of the desired temperature. Control is assisted by utilizing a thin layer of molten tin between the sample and the stage providing thermal contact during irradiation.

\section{Neutron Irradiation}

Although neutron irradiations are not a funded activity included on this NERI program, the alloys used on this program have been inserted in a neutron irradiation vehicle for possible future study. The long lead times for neutron irradiation do not allow their use in a short-term (3-year) program. It is anticipated that results from this program will point to successful ideas for alloys and will be of interest at a later date. Samples were prepared and submitted for irradiation in the Russian Boris reactor in February 2000 as a part of an industry-sponsored irradiation program. The dose for this irradiation will be $20 \mathrm{dpa}$ and will provide a reference for correlating the present high-dose ion irradiations with neutron irradiation. A second series of samples including the $316 \mathrm{SS}, 316 \mathrm{SS}+\mathrm{Pt}$ and $316 \mathrm{SS}+\mathrm{Hf}$ alloys were prepared and submitted in February 2001 for irradiation at doses of 5, 10 and $20 \mathrm{dpa}$. The first series of neutron irradiations may be available for characterization in 2002, while the more complete dose series will not be available until 2003 or 2004.

\section{Characterizations}

\section{Transmission Electron Microscopy (TEM) Procedures}

Damage resistance is primarily characterized using high-resolution analytical TEM. A particular challenge for examining ion-irradiated samples is the preparation of nearsurface regions to obtain well-defined dose levels. The depth of penetration of $5 \mathrm{MeV}$ $\mathrm{Ni}^{++}$ions into stainless steel is limited to about $1.5 \mu \mathrm{m}$ as shown in Figure 8. The optimum depth for examination is about $0.5 \mu \mathrm{m}$. At depths near $1 \mu \mathrm{m}$, the damage 
gradient is steep and therefore determination of the local dose is difficult. At depths less than $0.3 \mu \mathrm{m}$, the near presence of the surface influences the local damage causing it to be atypical of bulk radiation damage.

Prior to examination of irradiated samples, a technique was developed for precise thinning. The procedure included variations in polishing electrolyte composition, electric potential and geometry of the sample relative to the jet polishing stream. After each variation in condition, the measured depth of material removed was established using computerized Zygo interferometer. The interferometer displays the surface topology in a three-dimensional color format. An example of the polished crater is shown in Figure 9.

The projection enables precise evaluation of the depth and uniformity of polishing craters on the alloy surface. Once a large uniform area of depth is established, samples are thinned from the backside to perforation. This creates a significant area of electron transparent material for TEM examination.

After each irradiation, the sample was electropolished using a single-jet tenupol and a solution of $2 \%$ perchloric acid $+15 \%$ ethylene glycol $+83 \%$ methanol held at $-60^{\circ} \mathrm{C}$ and $25 \mathrm{~V}$ for $5 \mathrm{~s}$. This removed a $0.5-\mu \mathrm{m}$ layer from the irradiated surface and was followed by back-thinning from the non-irradiated side at $-55^{\circ} \mathrm{C}$ and $45 \mathrm{~V}$ till perforation.

\section{Summary of Microstructural Observations}

\section{$5 \mathrm{MeV} \mathrm{Ni}^{++}$ion irradiation at $500^{\circ} \mathrm{C}$}

The generally expected sequence of microstructural evolution was observed for these alloys with solute additions. The nucleation and growth of interstitial loops followed by the nucleation and growth of voids with increasing dose is supported by numerous observations in the literature. The thesis of the present research was confirmed indicating that a low concentration of large misfit atoms can alter the microstructural evolution path. Remarkably, void swelling was delayed in the $316+$ Hf alloy and completely suppressed to a dose of $50 \mathrm{dpa}$ in the $316+\mathrm{Hf}$ alloy with optimized heat treatment.

The Hf-containing alloy unexpectedly exhibited a high density of precipitates after the low temperature $\left(900^{\circ} \mathrm{C}\right)$ heat treatment. This fine-scale distribution transformed to a coarse-scale distribution and a much lower density after high temperature $\left(1100^{\circ} \mathrm{C}\right)$ heat treatment. The distribution of Hf in the matrix and the precipitates clearly affect the beneficial damage resistance of this alloy.

\section{Measured Microstructures from TEM}

The three alloys were characterized at doses of 0.5, 2.0, 10, 30 and $50 \mathrm{dpa}$. The nonirradiated alloy characterization confirmed the small grain size and the initial low density of network dislocations as shown in Figure 10. Irradiated alloys exhibited unique trends in the development of loop and void microstructures. Most interestingly for the Pt-doped alloy, the measured number of interstitials stored in loops progressed through a maximum near $2 \mathrm{dpa}$ and decreased significantly from 2 to $50 \mathrm{dpa}$. The base alloy and Hf-doped alloy showed no such maximum. In the case of the alloy containing $\mathrm{Hf}$, the $900^{\circ} \mathrm{C}(20$ 

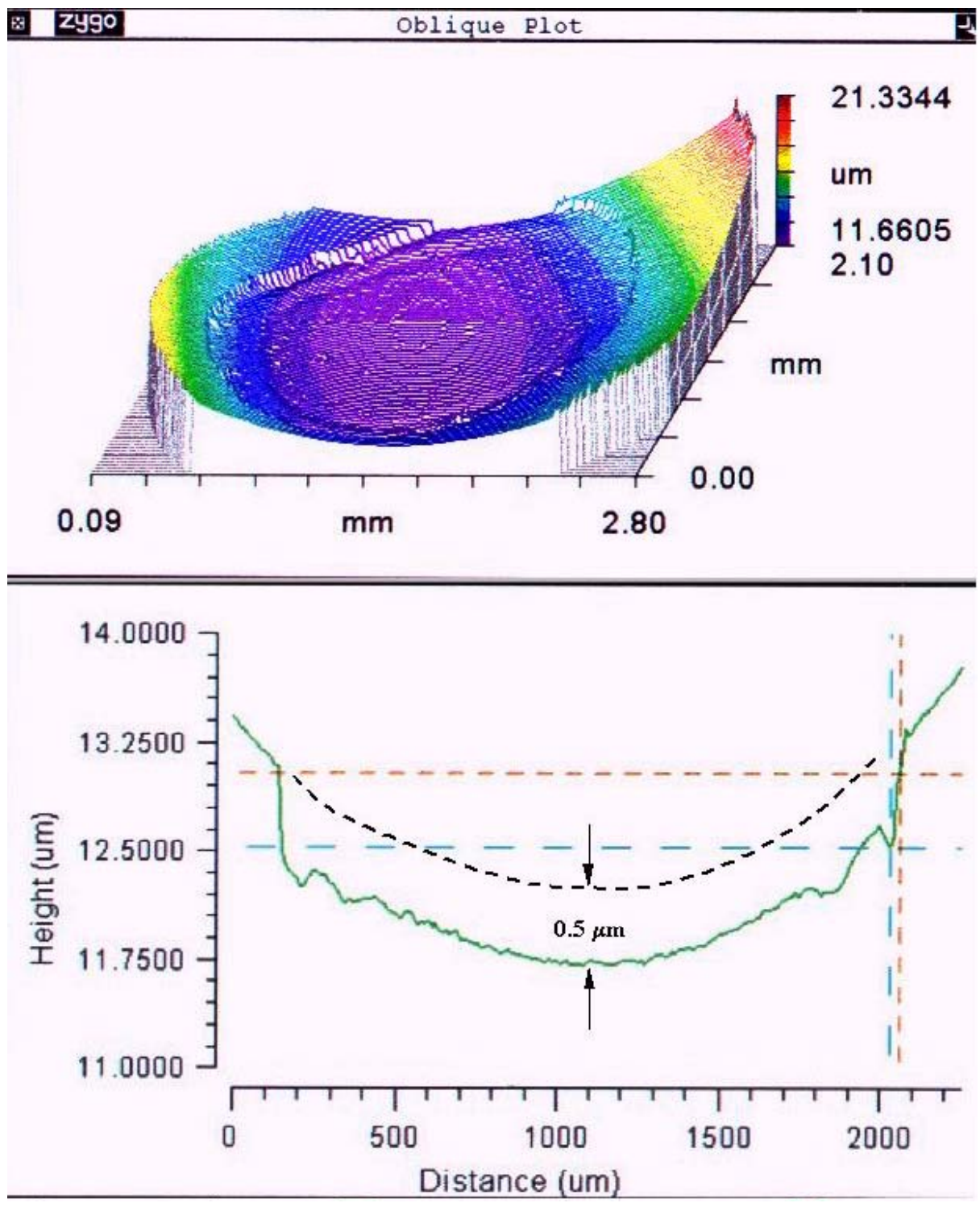

Figure 9. Profile of polishing crater showing uniform removal of a surface layer for precise examination of the ion-induced microstructure. Note that the vertical scale is about one thousand times smaller that the lateral scale.

min) heat-treated samples completely suppressed the swelling up to a dose of $10 \mathrm{dpa}$ while the samples with optimized heat-treatment at $1100^{\circ} \mathrm{C}(30 \mathrm{~min})$ completely suppressed the swelling at a dose $50 \mathrm{dpa}$. This indicates that $0.3 \mathrm{at} \% \mathrm{Hf}$ addition is very effective in altering the irradiated microstructure and the pre-existed precipitate structure also is important during microstructural evolution.

In the non-irradiated condition, the base alloy and the alloy with Pt addition revealed clean grain interiors with a low density of line dislocations. In contrast, the alloy with $\mathrm{Hf}$ addition revealed a fine distribution of Hf-rich precipitates as presented in Figure 10. It is expected that the Hf-rich phase precipitated during cooling from the solution annealing temperature and did not dissolve during the $900^{\circ} \mathrm{C} / 20 \mathrm{~min}$ heat treatment. An optimized 


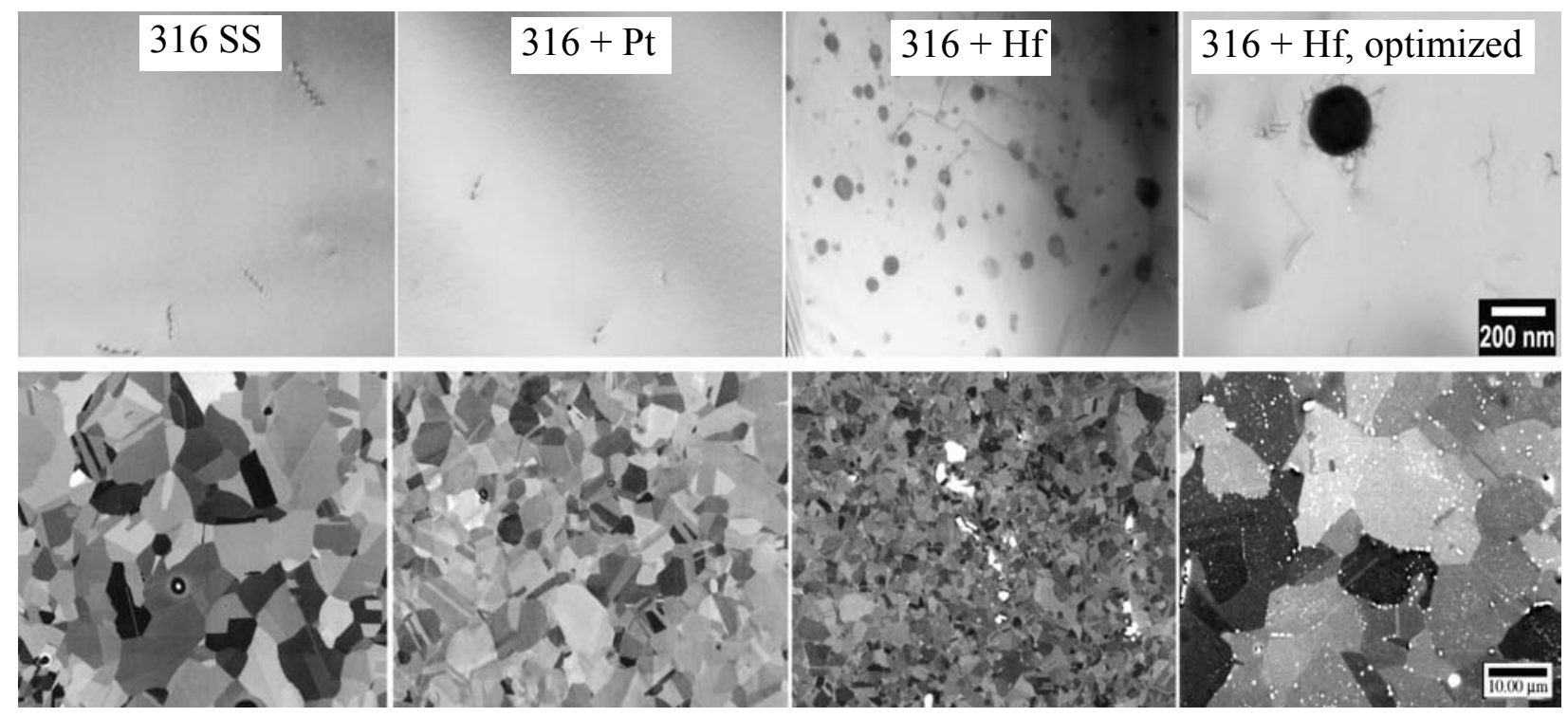

Figure 10. Micrographs show condition prior to irradiation. A low density of network dislocations is observed with precipitates only for the Hf alloy. The marker is $200 \mathrm{~nm}$ for TEM images (top) and $10 \mu \mathrm{m}$ for SEM images of grain structure (bottom).

heat treatment at $1100^{\circ} \mathrm{C} / 30 \mathrm{~min}$ substantially reduced the precipitate density by two orders of magnitudes.

The irradiated samples were imaged using a JEOL 2000. Three approaches were followed: (1) bright field loop imaging, (2) rel-rod loop imaging and (3) bright field void imaging. Examples of bright field loop images are shown in Figure. 11 for the three alloys irradiated to 0.5 to $50 \mathrm{dpa}$ with $5 \mathrm{MeV} \mathrm{Ni-ions} \mathrm{at} 500{ }^{\circ} \mathrm{C}$. Similarly, rel-rod dark field images and bright field void images are shown in Figures 12 and 13, respectively.

Quantitative microstructure measurements are included in Tables 5-7 for doses ranging from 0.5 to $50 \mathrm{dpa}$. The loop size and number density as a function of dose is shown in Figures 14 and 15. The characteristic feature of the dose dependence of the loop number density is the rapid increase to a maximum at low dose followed by a decrease with increasing dose from $2 \mathrm{dpa}$ to $10 \mathrm{dpa}$. The Hf-containing alloy revealed a high number density of loops at $50 \mathrm{dpa}$. The loop size dependence on dose followed a similar trend. The base alloy, however, did not exhibit a maximum at low dose. The interstitial volume fraction shown in Figure 16 reflects differences in aggregating interstitials into loops and differences in incorporation large loops into the network dislocation density for each of the three alloys. The alloys with elemental additions show a striking difference from the base alloy in that the interstitial fraction in loops has a maximum at $2 \mathrm{dpa}$ for alloy the $316+\mathrm{Pt}$ alloy but has a continuous increase with dose for the $316+\mathrm{Hf}$ alloy. This indicates that the elements are strongly affecting the loop formation and annihilation process at doses up to about $20 \mathrm{dpa}$. The optimized $316+\mathrm{Hf}$ alloy shows the least number of interstitials in loops. 

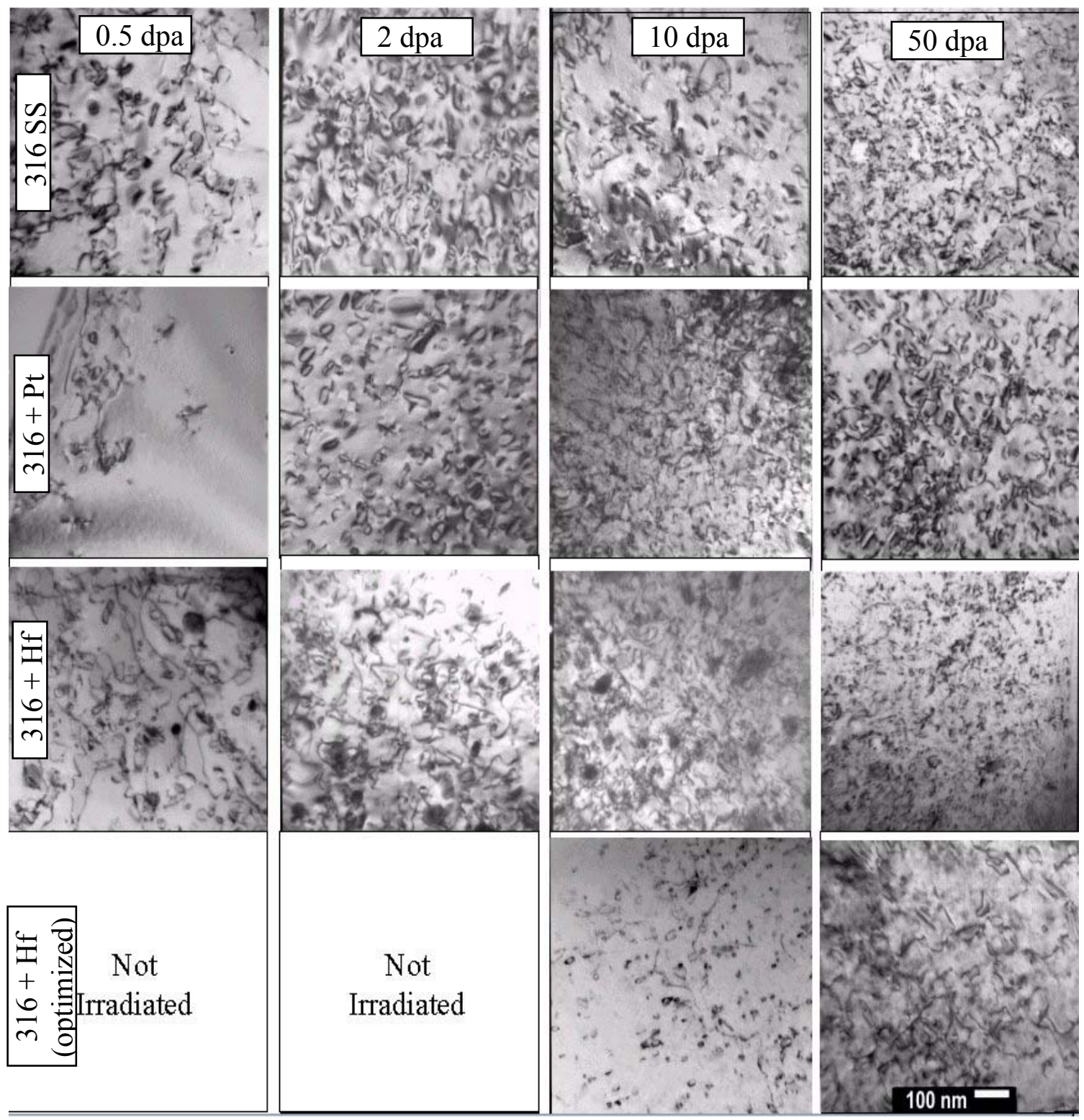

Figure 11. Bright-field micrographs of loop images for the three alloys irradiated to the indicated dose. Both faulted and unfaulted loops are imaged. Note the very high density of dislocation line length compared to the non-irradiated case. Larger loops of irregular geometry are unfaulted loops. The very dense image makes loop characterization difficult using bright-field techniques. The marker in the inset indicates $100 \mathrm{~nm}$. 


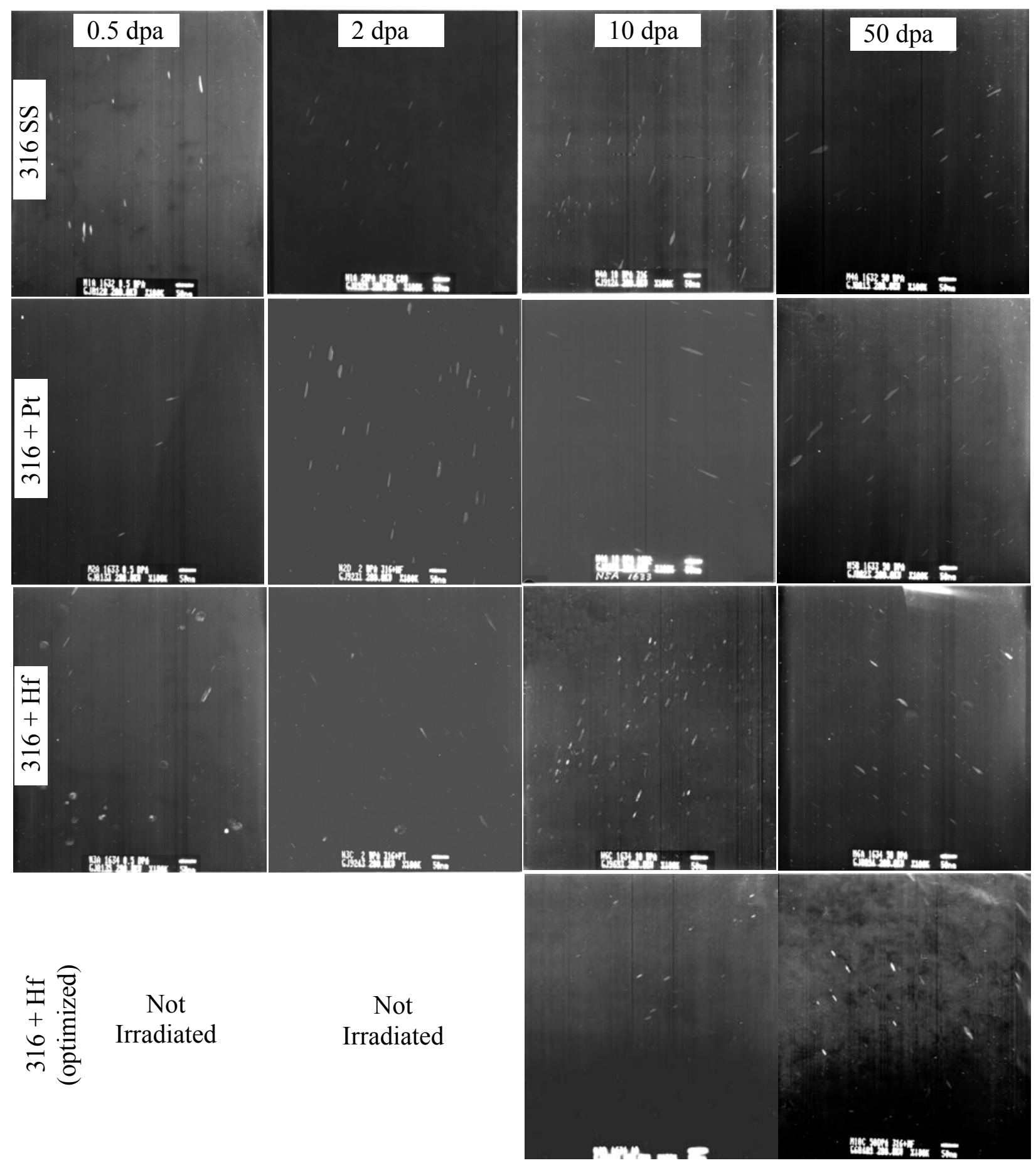

Figure 12. Rel-rod micrographs of loop images for the three alloys irradiated to the indicated doses. The short line segments are loop images. The rel-rod technique only images faulted dislocation loops.

Because of diffraction conditions, only $1 / 4$ of the loops can be imaged for one specimen orientation. This technique provides better visibility for identifying individual loops. The marker in the inset indicates 50 $\mathrm{nm}$. 

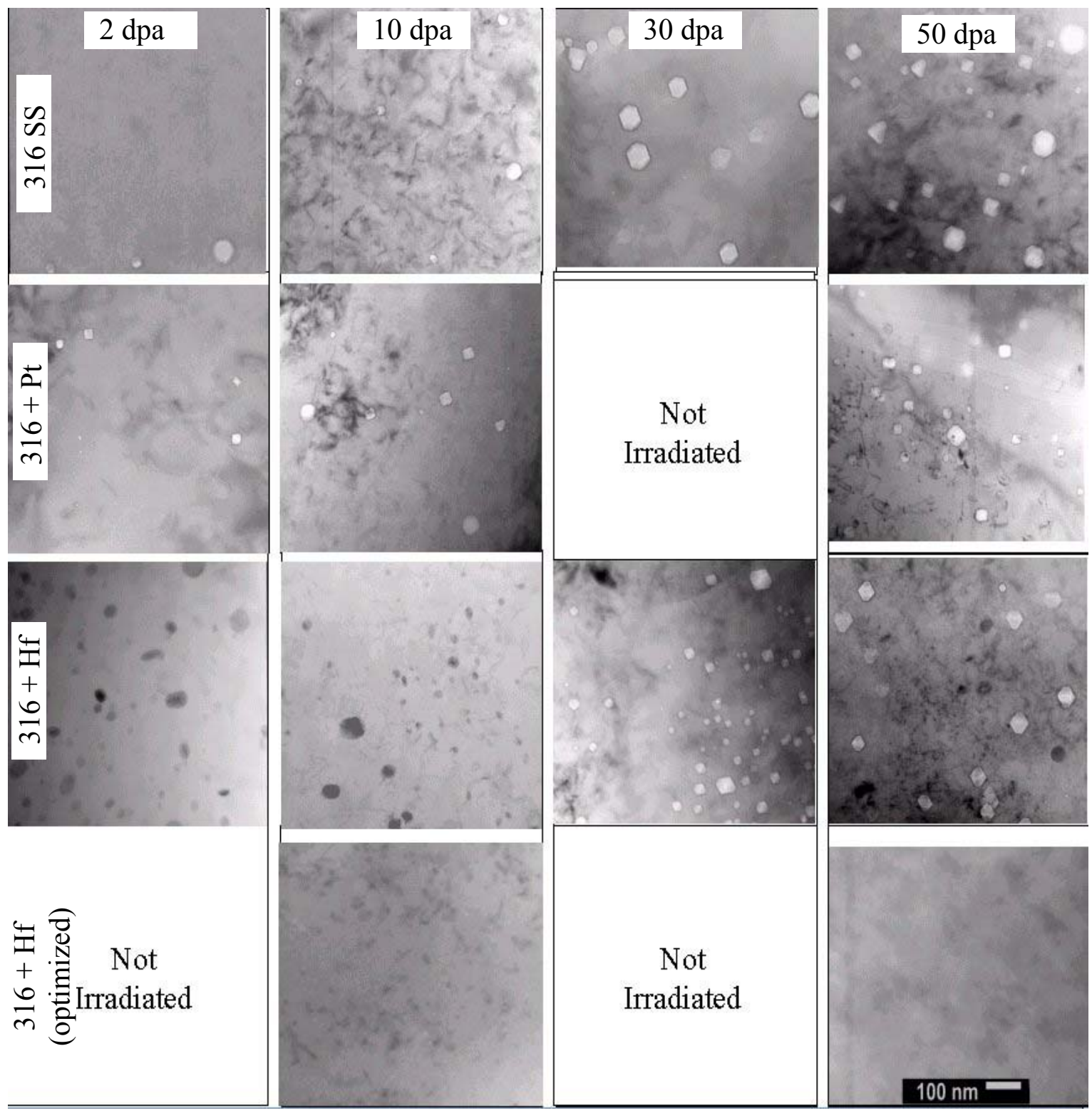

Figure 13. Micrographs of voids for the three alloys irradiated to the indicated doses. Voids show up as white images. Voids are only predominant at $50 \mathrm{dpa}$. The density was marginally high enough to obtain an estimate at $10 \mathrm{dpa}$ for the Pt containing alloy. For the Pt- and Hf-containing alloys, the images shown represent local areas of higher void density. Typically, a significant fraction of the areas examined showed no voids. The base alloy exhibited a uniform void distribution represented in the figure. The marker in the inset indicates $100 \mathrm{~nm}$.

The size distributions of the loops are shown in Figure 17. The loop sizes ranged up to $70 \mathrm{~nm}$. The interesting feature in the dose dependence for the Hf-containing alloy is the presence of large loops at low dose but an absence of large loops at high dose. This indicates that the precipitates inhibit unfaulting at low doses but not at high doses. The effect of large misfit solutes on unfaulting behavior may be a key issue in modifying radiation microstructures. Loop development is necessary as a precursor to steady-state swelling. 
Table 5. Loop number density and size as a function of dose.

\begin{tabular}{|c|c|c|c|c|c|c|c|c|}
\hline \multirow[t]{2}{*}{$\begin{array}{l}\text { Dose } \\
\text { (dpa) }\end{array}$} & $316 \mathrm{~L} \mathrm{SS}$ & $316 \mathrm{~L}+\mathrm{Pt}$ & $316 \mathrm{~L}+\mathrm{Hf}$ & $\begin{array}{l}316 \mathrm{~L}+\mathrm{Hf} \\
\text { (optimized) }\end{array}$ & $316 \mathrm{~L} \mathrm{SS}$ & $316 \mathrm{~L}+\mathrm{Pt}$ & $316 \mathrm{~L}+\mathrm{Hf}$ & $\begin{array}{c}316 \mathrm{~L}+\mathrm{Hf} \\
\text { (optimized) }\end{array}$ \\
\hline & loops $/ \mathrm{cm}^{3}$ & loops $/ \mathrm{cm}^{3}$ & loops $/ \mathrm{cm}^{3}$ & loops $/ \mathrm{cm}^{3}$ & dia., nm & dia., $n m$ & dia., $\mathrm{nm}$ & dia., $\mathrm{nm}$ \\
\hline 0.0 & 0 & 0 & 0 & 0 & 0 & 0 & 0 & 0 \\
\hline 0.5 & $4.3 \mathrm{E}+14$ & $2.9 \mathrm{E}+14$ & $6.0 \mathrm{E}+14$ & -- & 22 & 22 & 17 & -- \\
\hline 2.0 & $9.4 \mathrm{E}+14$ & $1.5 \mathrm{E}+15$ & $9.6 \mathrm{E}+14$ & -- & 24 & 32 & 15 & -- \\
\hline 10 & $6.9 \mathrm{E}+14$ & $1.1 \mathrm{E}+15$ & $2.3 E+15$ & $8.2 \mathrm{E}+14$ & 25 & 28 & 14 & 14 \\
\hline 30 & $7.4 \mathrm{E}+14$ & -- & $4.5 \mathrm{E}+15$ & -- & 25 & -- & 13 & -- \\
\hline 50 & $8.8 \mathrm{E}+14$ & $1.1 \mathrm{E}+15$ & $5.8 \mathrm{E}+15$ & $1.9 \mathrm{E}+15$ & 25 & 20 & 13 & 16 \\
\hline
\end{tabular}

Table 6(a). Void number density and size as a function of dose.

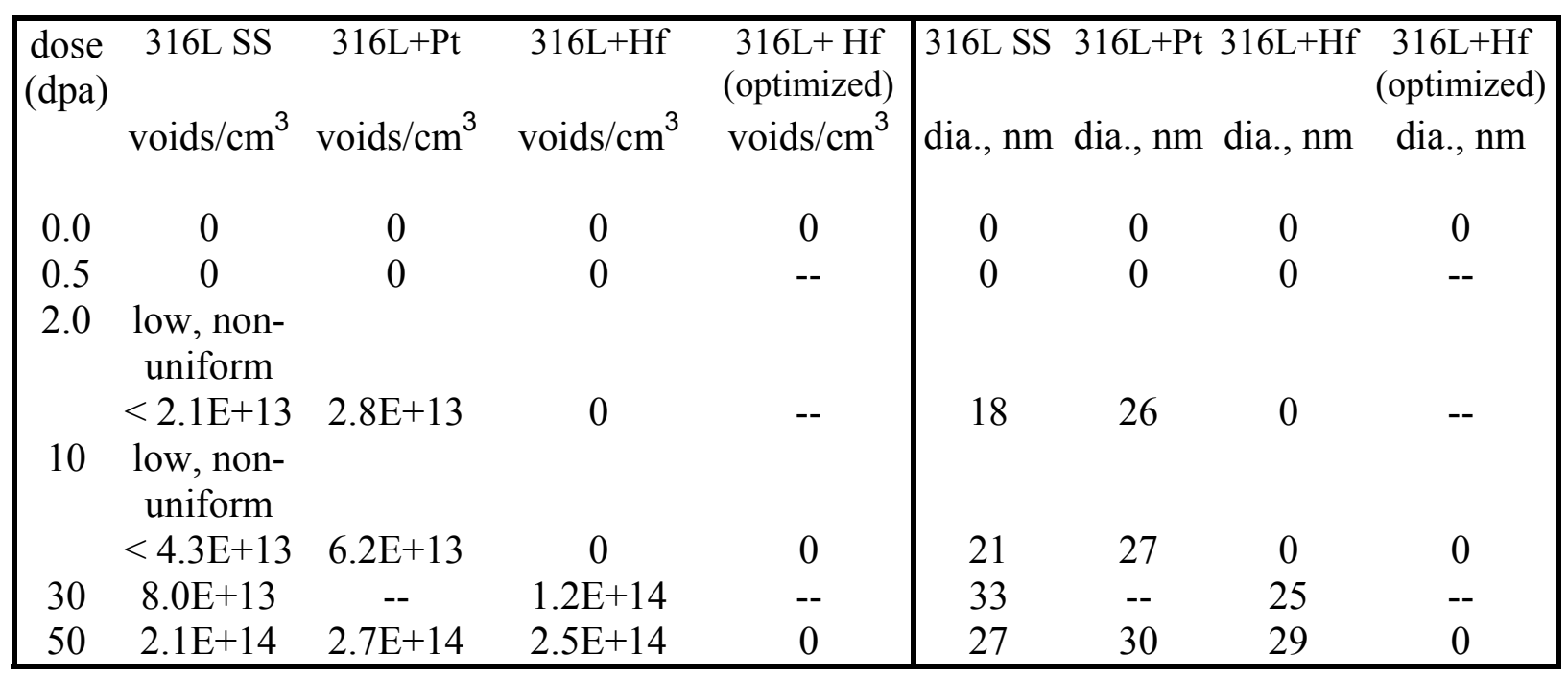

Table 6(b) Void swelling as a function of dose

\begin{tabular}{|ccccc|}
\hline $\begin{array}{c}\text { Dose } \\
\text { (dpa) }\end{array}$ & $\begin{array}{c}316 \mathrm{~L}+\mathrm{Hf} \\
(\%)\end{array}$ & $\begin{array}{c}316 \mathrm{~L}+\mathrm{Pt} \\
(\%)\end{array}$ & $\begin{array}{c}316 \mathrm{~L}+\mathrm{Hf} \\
(\%)\end{array}$ & $\begin{array}{c}316 \mathrm{~L}+\mathrm{Hf} \\
\text { (optimized) } \\
(\%)\end{array}$ \\
0.0 & 0 & 0 & 0 & 0 \\
0.5 & 0 & 0 & 0 & -- \\
2.0 & 0.01 & 0.03 & 0 & -- \\
10 & 0.03 & 0.09 & 0 & 0 \\
30 & 0.26 & -- & 0.15 & -- \\
50 & 0.46 & 0.65 & 0.45 & 0 \\
\hline
\end{tabular}


Table 7. Hf precipitate number density, size and volume as a function of dose.

\begin{tabular}{|ccc|cc|cc|}
\hline $\begin{array}{c}\text { Dose } \\
\text { (dpa) }\end{array}$ & $316 \mathrm{~L}+\mathrm{Hf}$ & $\begin{array}{c}316 \mathrm{~L}+\mathrm{Hf} \\
\text { (optimized) } \\
\mathrm{ppt} / \mathrm{cm}^{3}\end{array}$ & 316L+Hf & $\begin{array}{c}316 \mathrm{~L}+\mathrm{Hf} \\
\text { dia., nm }\end{array}$ & $\begin{array}{c}316+\mathrm{Hf} \\
\text { dia., } \mathrm{nm}\end{array}$ & $\begin{array}{c}316 \mathrm{~L}+\mathrm{Hf} \\
\text { (optimized) } \\
\text { vol., } \mathrm{nm}^{3}\end{array}$ \\
0.0 & $6.5 \mathrm{E}+14$ & $9.6 \mathrm{E}+12$ & 20 & 129 & $1.06 \mathrm{E}+4$ & $2.6 \mathrm{E}+6$ \\
0.5 & $8.6 \mathrm{E}+14$ & -- & 22 & -- & $0.95 \mathrm{E}+4$ & -- \\
2.0 & $8.6 \mathrm{E}+14$ & -- & 20 & -- & $0.93 \mathrm{E}+4$ & -- \\
10 & $6.0 \mathrm{E}+14$ & $4.0 \mathrm{E}+12$ & 22 & 111 & $1.05 \mathrm{E}+4$ & $1.4 \mathrm{E}+6$ \\
30 & $2.0 \mathrm{E}+14$ & -- & 26 & -- & $1.76 \mathrm{E}+4$ & -- \\
50 & $1.9 \mathrm{E}+14$ & $8.5 \mathrm{E}+12$ & 26 & 105 & $2.46 \mathrm{E}+4$ & $1.6 \mathrm{E}+6$ \\
\hline
\end{tabular}

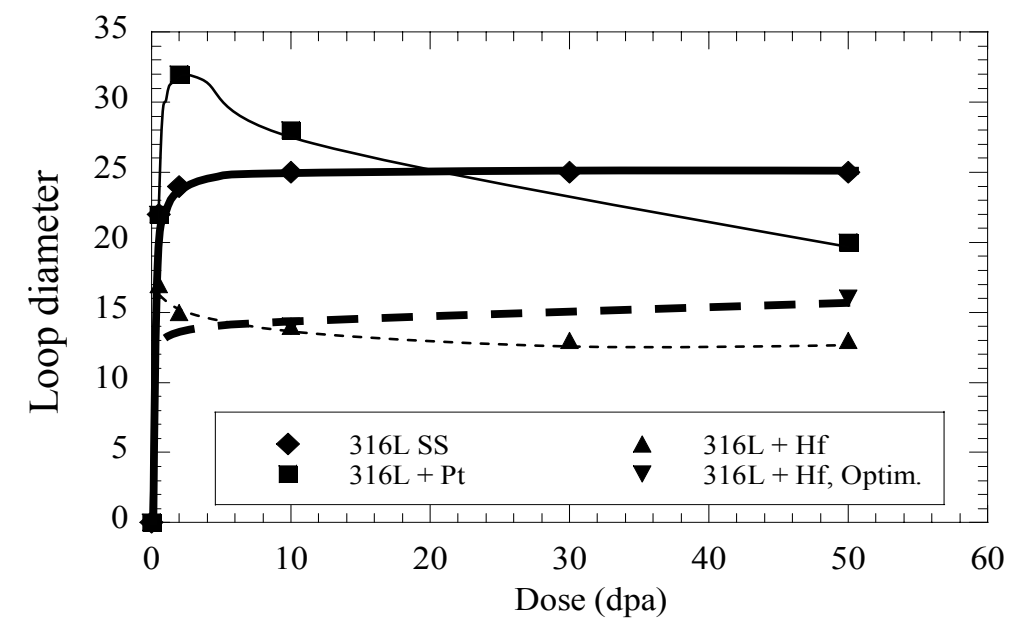

Figure 14. Loop size as a function of dose for the three alloys. The loop size decreases from 2 to $10 \mathrm{dpa}$ because of unfaulting of large loops. After unfaulting these loops glide and become integrated in the network dislocation line length.

The measured void number densities were very low, often non-uniform and difficult to characterize statistically. The base alloy revealed a low number density of non-uniform voids up to $10 \mathrm{dpa}$ but revealed a large size and high number density at $50 \mathrm{dpa}$ as seen in Figures 18 and 19, respectively. The Pt-containing alloy revealed a void density higher than base alloy. The alloy $316+$ Hf delayed void swelling up to dose 10 dpa while the optimized ally $316+\mathrm{Hf}$ completely suppressed the void swelling up to dose $50 \mathrm{dpa}$. Measured void sizes in these alloys ranged from $18 \mathrm{~nm}$ to $33 \mathrm{~nm}$ as indicated in the Table 3. The dependence of void volume fraction (swelling) on dose is shown in Figure 20. At high dose, three of the alloys swell at similar swelling rates while there is no swelling in the optimized $316+\mathrm{Hf}$ alloy.

The size distributions of the voids at 50 dpa are shown in Figure 21. Void size distributions could only be characterized at 50 dpa because of the lack of voids at the other conditions. The void sizes ranged up to $70 \mathrm{~nm}$. Interestingly, the Hf-containing alloy is the narrower size distribution compared to the other alloys. 


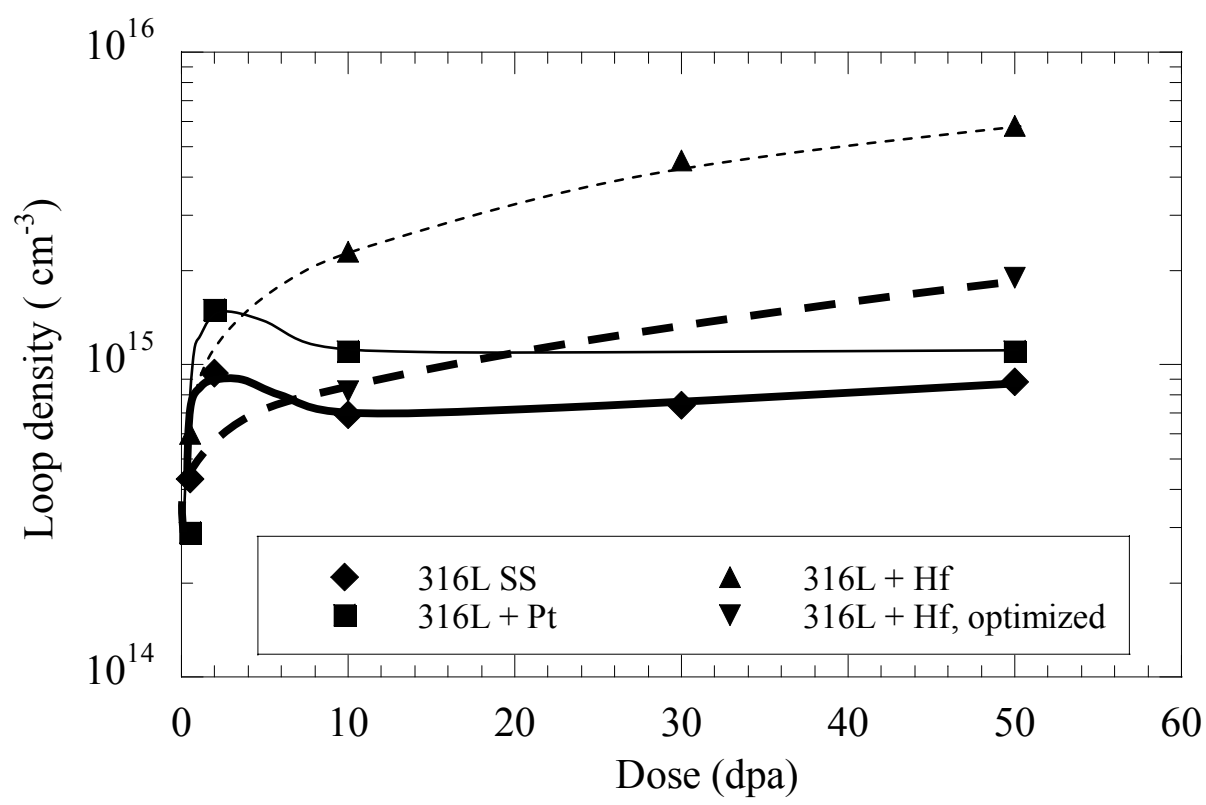

Figure 15. Loop number density as a function of dose for the three alloys. The loop number density decreases from 2 to $10 \mathrm{dpa}$ because of unfaulting of large loops. After unfaulting these loops glide and become integrated in the network dislocation line length.

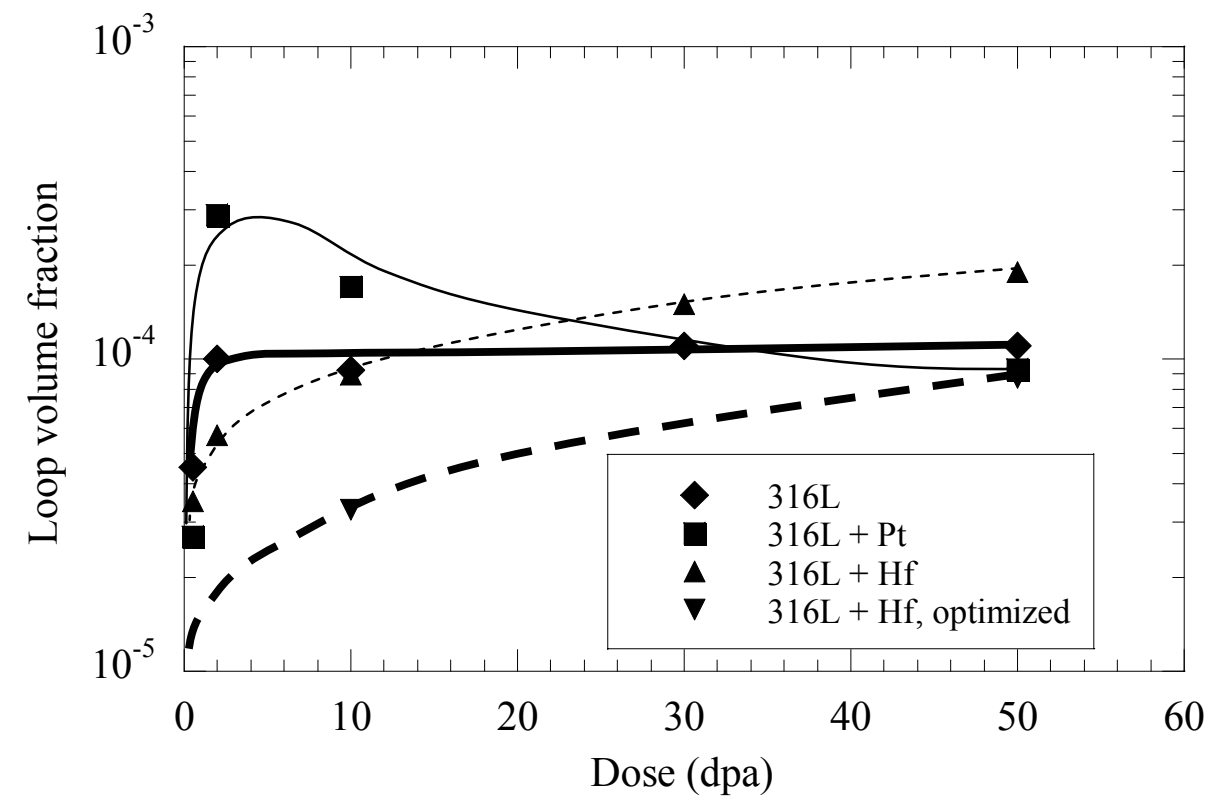

Figure 16. The loop volume fraction is shown as a function of dose for the three alloys. The capacity to store interstitials in loops passes through a strong transient between 0 and $10 \mathrm{dpa}$ for the alloys with Pt or Hf additions but not for the base alloy.

The Hf-containing alloys exhibited a distribution of Hf-rich precipitates in the nonirradiated condition. The effect of increasing dose on the precipitate number density and size is shown in Figure 22 for the 316+Hf alloy. The number density decreases as the size increases up to a dose of $30 \mathrm{dpa}$ and then stabilized between $30 \mathrm{dpa}$ and $50 \mathrm{dpa}$. However, as shown in Table 4 the mean volume of the precipitates remains nearly constant up to $10 \mathrm{dpa}$, then increases by a factor of $\sim 2.5$ from $10 \mathrm{dpa}$ to $50 \mathrm{dpa}$ at which 

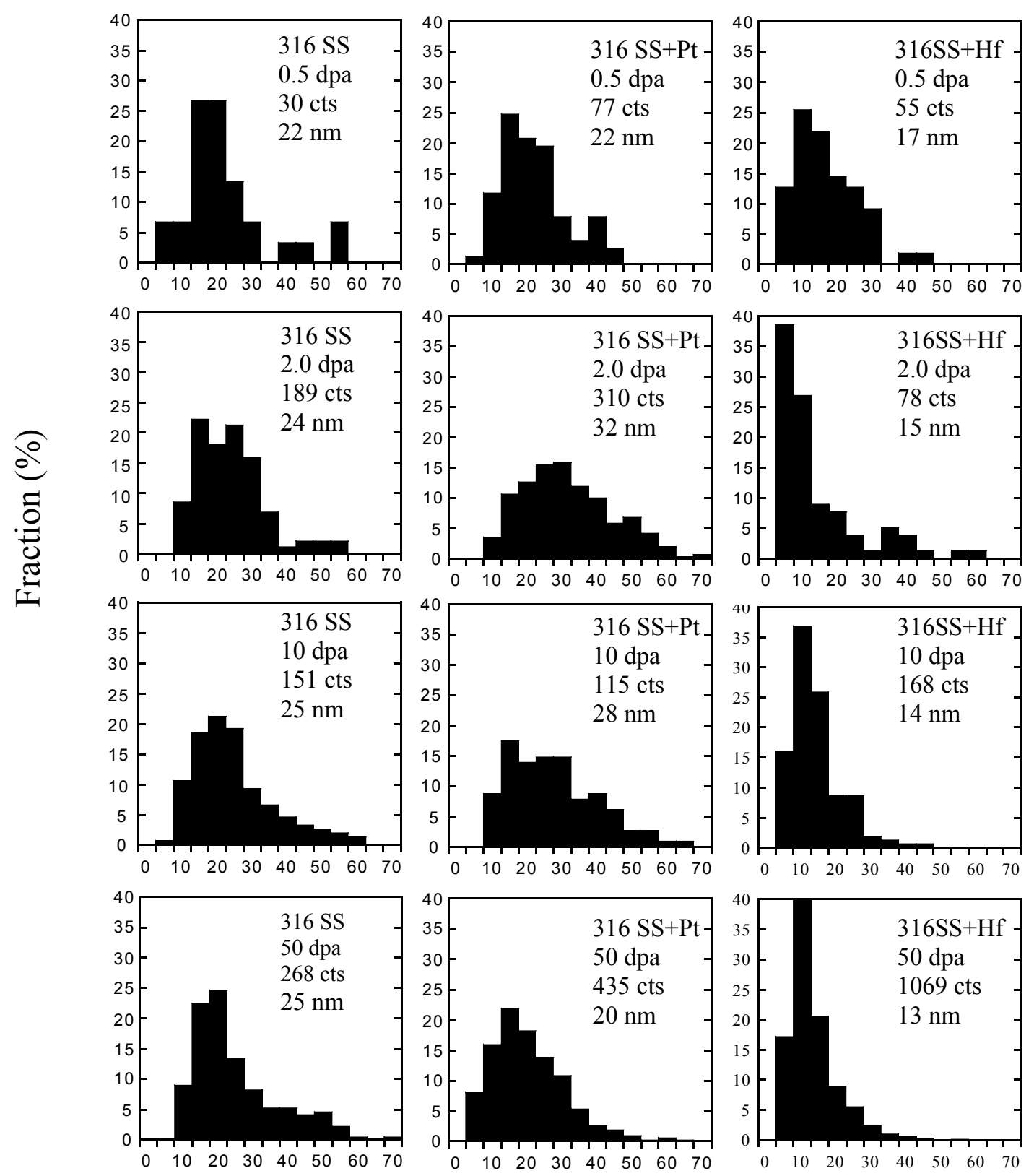

Diameter (nm)

Figure 17. The faulted loop size distributions are shown as a function of alloy and dpa from 0.5 to $50 \mathrm{dpa}$. The average loop size in insensitive to dose $(15-30 \mathrm{~nm})$. The tail in the distribution is likely caused by unfaulting near $60 \mathrm{~nm}$ followed by adsorption in the network dislocations.

dose the voids were observed in alloy $316+\mathrm{Hf}$ (heat treated at $900^{\circ} \mathrm{C}$ for $20 \mathrm{~min}$ ). The change of precipitate structure may play an important role in the development of the irradiated microstructure. This indicates that the irradiation behavior is influenced by both $\mathrm{Hf}$ in solution and by $\mathrm{Hf}$ precipitates. The evolution of precipitate structure between doses of $10 \mathrm{dpa}$ to 50 dpa likely contributes to the continuous increase of loop density in the Hf containing alloy to $50 \mathrm{dpa}$. 


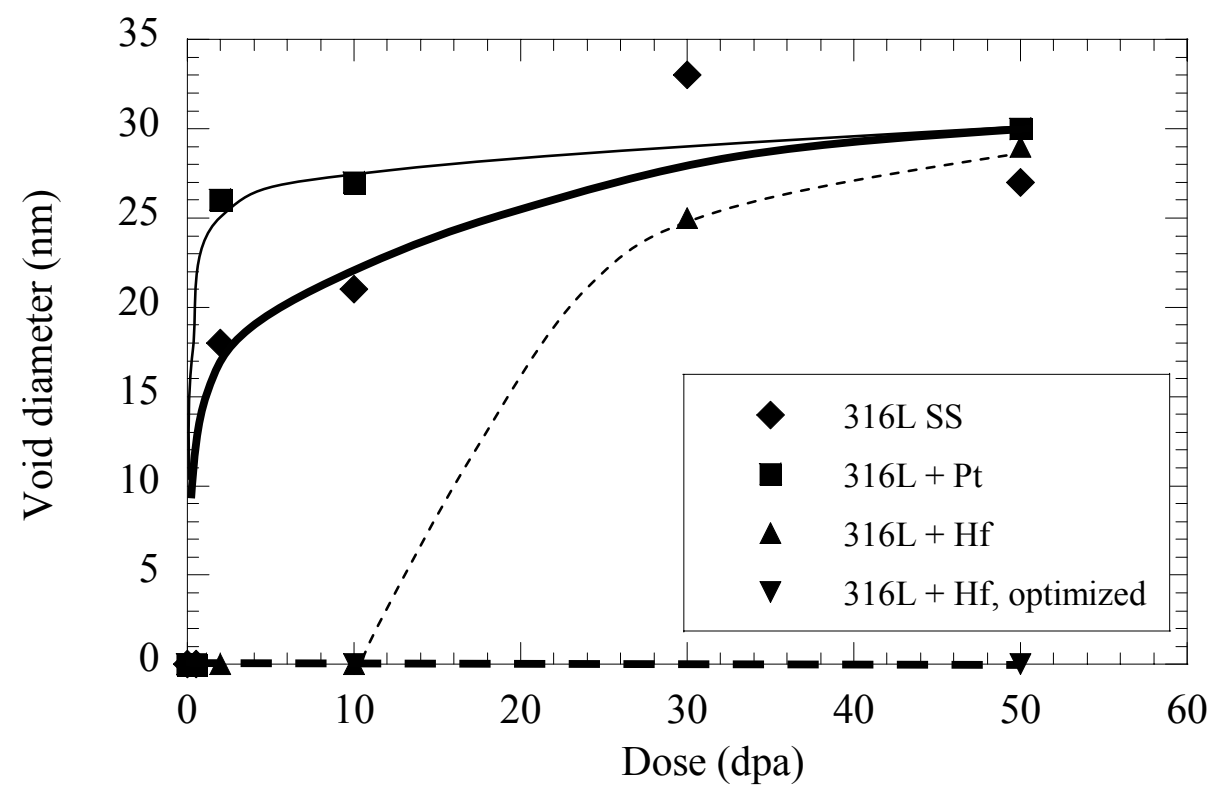

Figure 18. Measured void size as a function of dose.

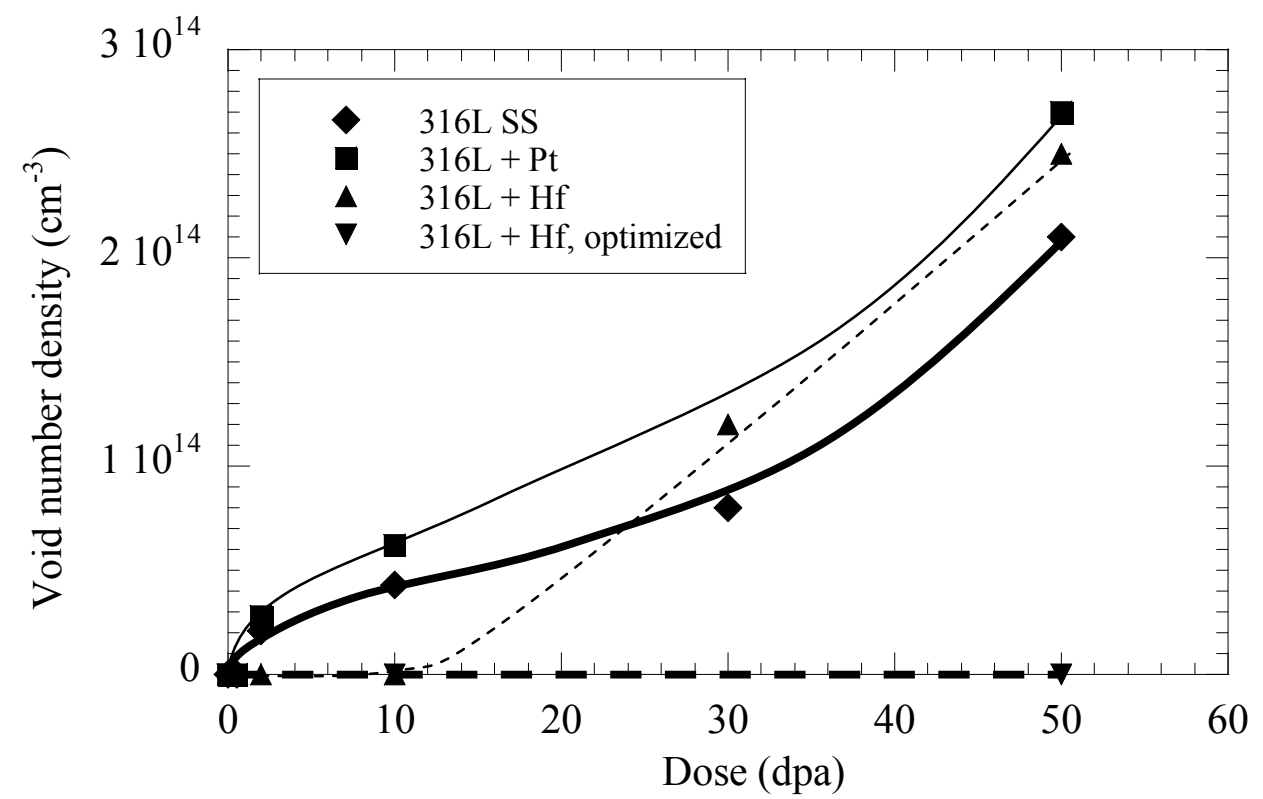

Figure 19. Measured void number density as a function of dose. The base alloy exhibits a much greater void number density at 50 dpa compared to the alloys with Pt or Hf additions.

The $316+\mathrm{Hf}$ alloy optimized using a higher temperature heat treatment $\left(1100^{\circ} \mathrm{C}\right.$ for 30 min.) demonstrated that by reducing the precipitate density down to below $10^{13} / \mathrm{cm}^{3}$, the $\mathrm{Hf}$ doped alloy postponed the void microstructure beyond $50 \mathrm{dpa}$. In additional, loop microstructure is delayed in the $316+\mathrm{Hf}$ optimized alloy, shown in Figure 16. It is clear that reduction or elimination of the Hf-enriched precipitate microstructure in the $316+\mathrm{Hf}$ alloy significantly improves the alloy preformance by suppressing the irradiated microstructure. The comparison of precipitate microstructure as a function of dose 


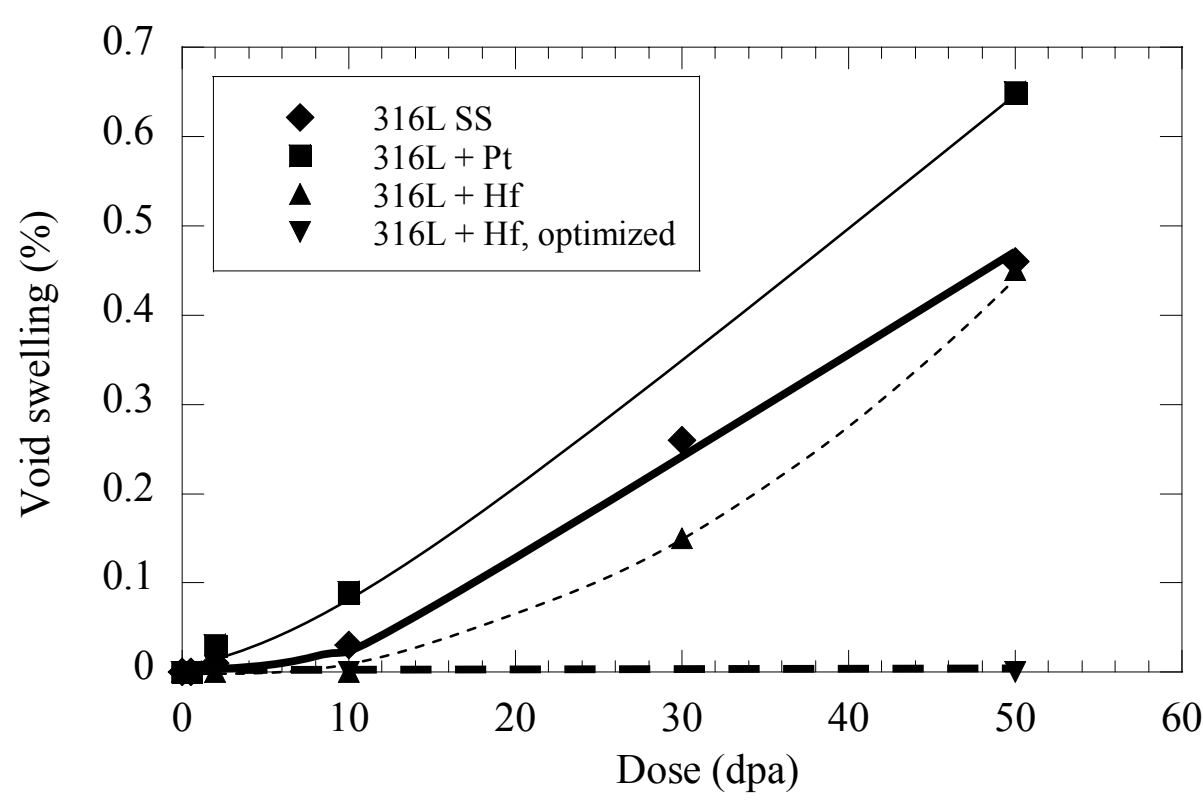

Figure 20. Measured void volume fraction (swelling) is shown as a function of dose. The alloys with Pt or Hf additions had very non-uniform distributions and therefore the actual swelling is less than indicated.

between the $316+\mathrm{Hf}$ alloy and the optimized $316+\mathrm{Hf}$ alloy is shown in Figure 23. Note that the precipiate density in the optimized alloy is below $10^{13} / \mathrm{cm}^{3}$, which is at the lower limit for the number density measurement using TEM analysis.

\subsection{MeV proton irradiation at $400^{\circ} \mathrm{C}$}

The effect of oversized solute atom additions ( $0.3 \mathrm{at} \% \mathrm{Pt}, 0.3 \mathrm{at} \% \mathrm{Hf})$ on the irradiated microstructure is also investigated using proton irradiation at $400^{\circ} \mathrm{C}$ to a dose $2.5 \mathrm{dpa}$. For the Hf-doped alloy, only the optimized $316+\mathrm{Hf}$ was used. The penetration depth and uniform damaged profile for $3.2 \mathrm{MeV}$ protons in austenitic stainless steel is about $40 \mu \mathrm{m}$ and $35 \mu \mathrm{m}$, respectively. The microstructure was examined at a depth of $10 \mu \mathrm{m}$ from the surface. The results of the irradiated microstructure are shown in Table 8.

The results from proton irradiation at $400^{\circ} \mathrm{C}$ to a dose of $2.5 \mathrm{dpa}$ are in good agreement with Ni-ion irradiation at $500^{\circ} \mathrm{C}$ to doses of 2 and $10 \mathrm{dpa}$. The $316+\mathrm{Pt}$ alloy has a larger loop size, higher void density with larger void size than base alloy and the $316+\mathrm{Hf}$ alloy has a smaller loop size and no voids for both types of irradiation. The loops and voids in the 316+Pt alloy after Ni ion-irradiation to doses of $2 \mathrm{dpa}$ and $10 \mathrm{dpa}$ and protonirradiated to a dose of 2.5 dpa are shown in Figure 24. The comparison of the results between Ni ion and proton irradiation is shown in Figure 25(a) to (e). Note that the void number density in the proton-irradiated 316+Pt alloy at dose of $2.5 \mathrm{dpa}$ is much higher than for Ni-ion irradiation at a comparable dose. Pt promotes void nucleation and point defects recombination simultaneously as the irradiation proceeded. The latter effect can be seen from the reduced RIS in alloy $316+\mathrm{Pt}$ that is discussed later in this report.

Ni-ion irradiation and proton irradiation has significant differences in cascade 

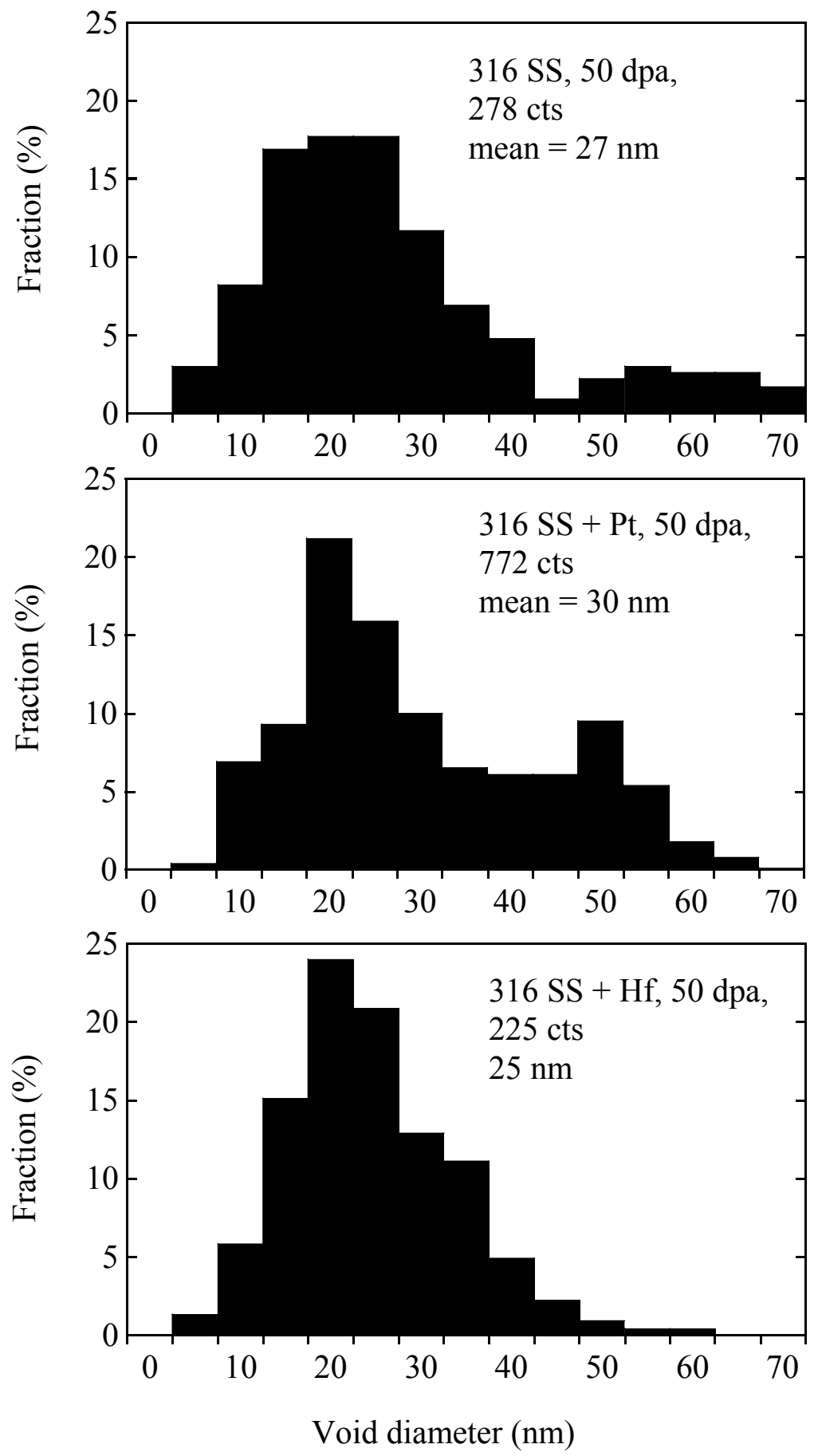

Figure 21. Void size distribtuion at $50 \mathrm{dpa}$ for the three alloys under investigation. The apparent bimodal distribution in the Pt-containing alloy may be an artifact of the low counts used for the distribution.

morphology. If oversized solute addition mainly affect the cascade process, $\mathrm{Ni}$-ion irradiation should show stronger effects than proton irradiation. The good agreement between the two different types of irradiation indicates the major effect of the oversized solute addition is not in the cascade process but in the post-cascade defects partitioning to the microstructure evolution and microchemistry development at the grain boundaries. 


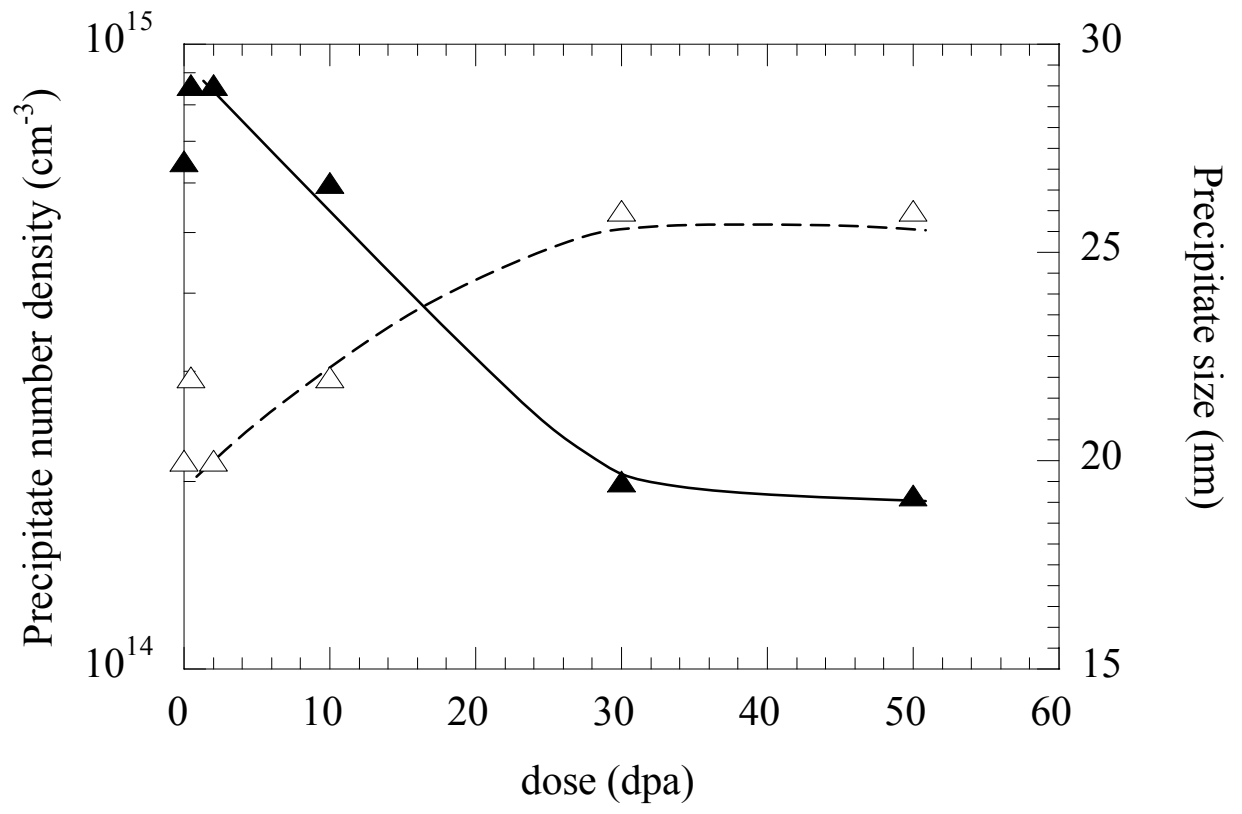

Figure 22. Measured size and number density of Hf-containing precipitates. A significant coarsening of the precipitate distribution is observe.

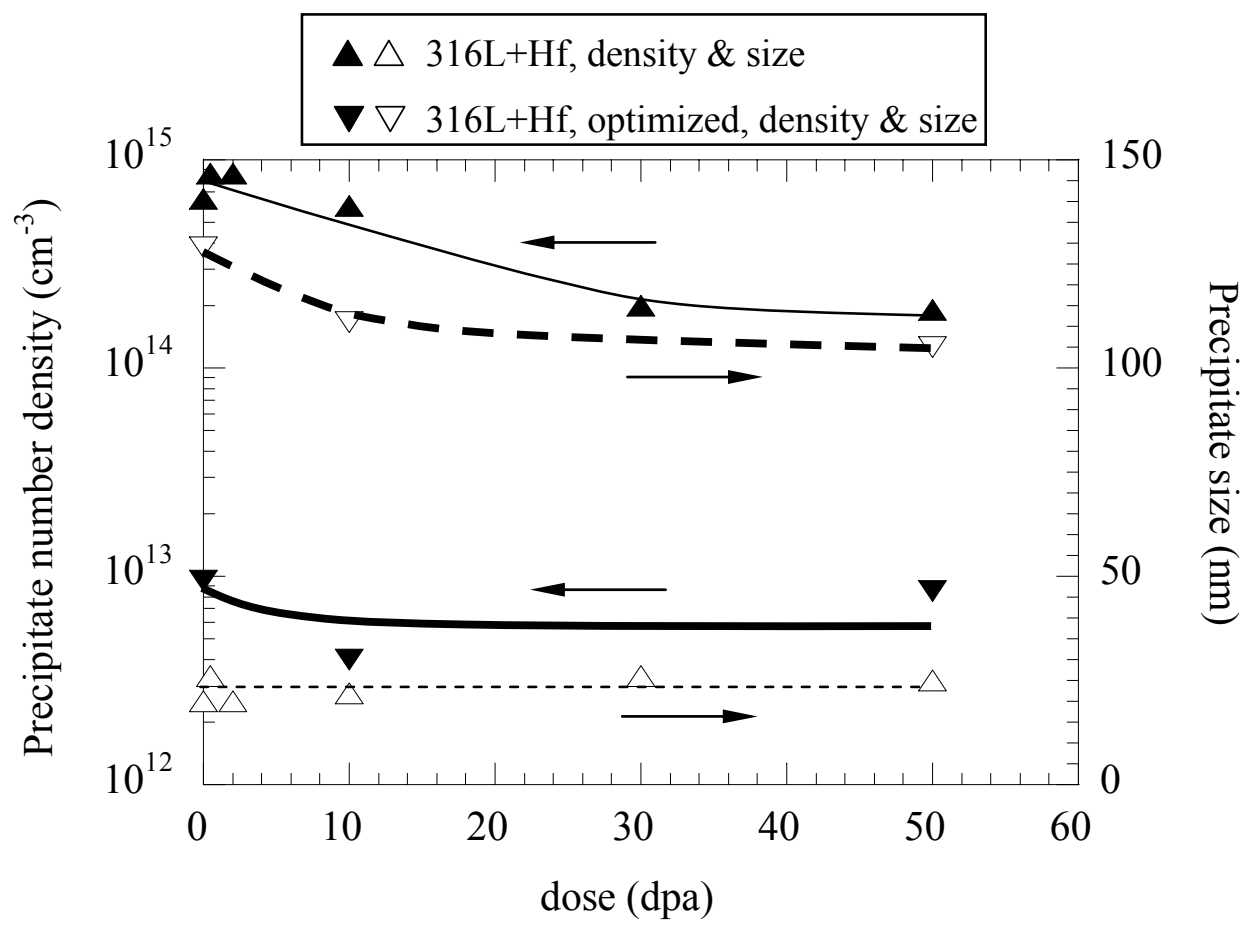

Figure 23. Measured size and number density of Hf-containing precipitates. A significant coarsening of the precipitate distribution is observe. 
Table 8. Results of irradiated microstructure for proton irradiation at $400^{\circ} \mathrm{C}$ to $2.5 \mathrm{dpa}$

\begin{tabular}{|c|c|c|cc|c|}
\hline Alloy & $\begin{array}{c}\text { Loop } \\
\text { loops } / \mathrm{cm}^{3}\end{array}$ & $\mathrm{~nm}$ & $\begin{array}{c}\text { Void } \\
\text { voids } / \mathrm{cm}^{3}\end{array}$ & $\mathrm{~nm}$ & $\begin{array}{c}\text { Swelling } \\
(\%)\end{array}$ \\
316 base & $9.5 \mathrm{E}+14$ & 30 & $1.0 \mathrm{E}+14$ & 13 & 0.03 \\
$316+\mathrm{Pt}$ & $1.2 \mathrm{E}+15$ & 38 & $4.0 \mathrm{E}+14$ & 18 & 0.13 \\
$316+\mathrm{Hf}$, optimized & $3.1 \mathrm{E}+15$ & 13 & 0 & 0 & 0 \\
\hline
\end{tabular}

Ni ion irradiation

2 dpa
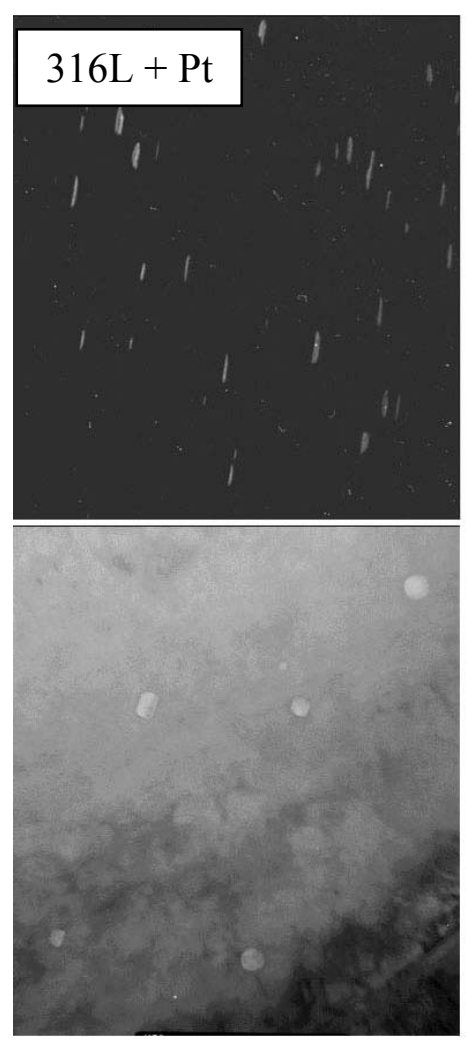

Figure 24. Comparison of the irradiated microstructure showing Frank loops and voids in $\mathrm{Ni}^{++}$irradiated and proton-irradiated alloy $316+\mathrm{Pt}$ at comparable doses.
Proton irradiation

$2.5 \mathrm{dpa}$
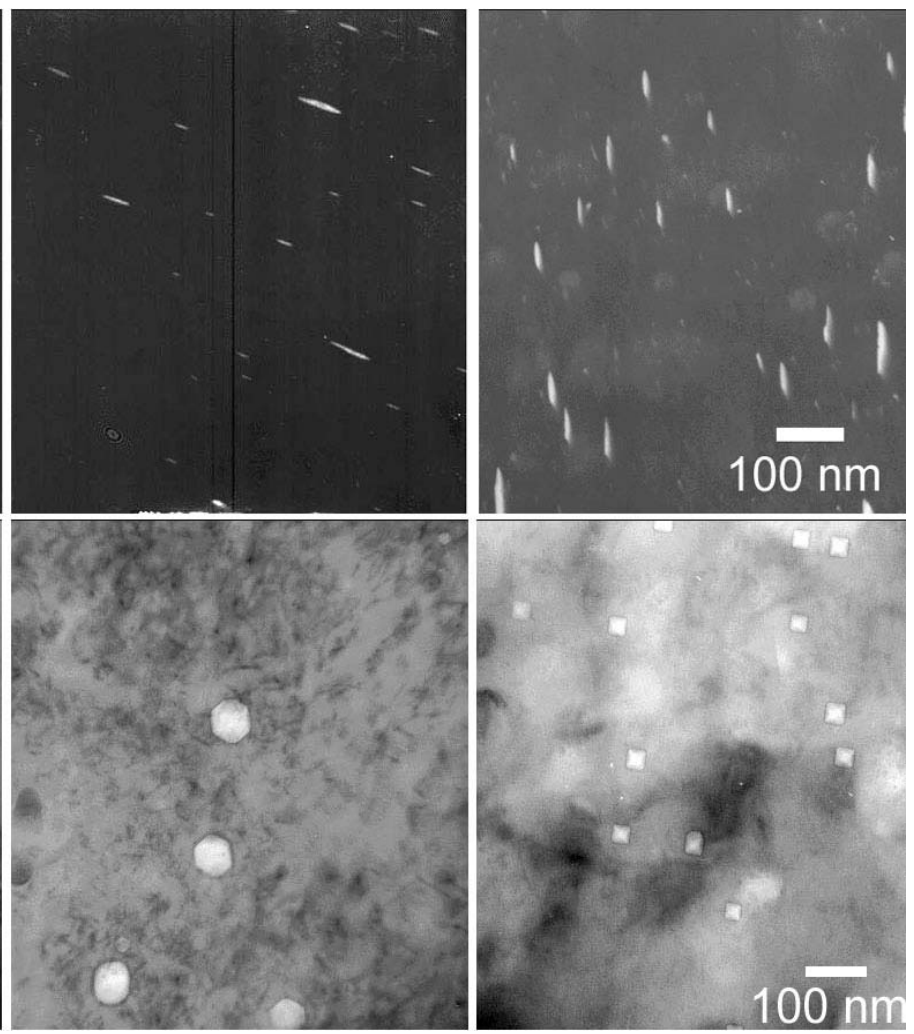

\section{Microchemical Characterization - Proton Irradiation}

The results of grain boundary composition measurements of 316SS, 316SS+Pt and $316 \mathrm{SS}+\mathrm{Hf}$ optimized alloys proton-irradiated to $2.5 \mathrm{dpa}$ at $400^{\circ} \mathrm{C}$ are listed in Table 9. In addition, typical comparative grain boundary composition profiles for $316 \mathrm{SS}, 316 \mathrm{SS}+\mathrm{Pt}$ and $316 \mathrm{SS}+\mathrm{Hf}$ optimized alloys proton-irradiated to $2.5 \mathrm{dpa}$ at $400^{\circ} \mathrm{C}$ are shown in Figure 26 for $\mathrm{Cr}, \mathrm{Fe}, \mathrm{Ni}, \mathrm{Mo}, \mathrm{Mn}$ and $\mathrm{Si}$. Clearly, measured grain boundary composition profiles were quite different from one alloy to another. 
Strong RIS of alloying elements and impurities was observed for the 316SS alloy. Cr, Fe, Mo and Mn concentrations at the grain boundary are depleted while Ni and Si are enriched after irradiation. The composition profiles of the alloying elements are nearly symmetrical, decaying to near-matrix levels within a few $\mathrm{nm}(<10 \mathrm{~nm})$ from the grain boundary. RIS was also observed for the $316 \mathrm{SS}+\mathrm{Pt}$ alloy but the amount of segregation was significantly lower than for the 316SS alloy. Conversely these profiles indicate, little RIS of alloying elements or impurities for the $316 \mathrm{SS}+\mathrm{Hf}$ optimized alloy, suggesting that Hf addition is very effective in suppressing RIS.
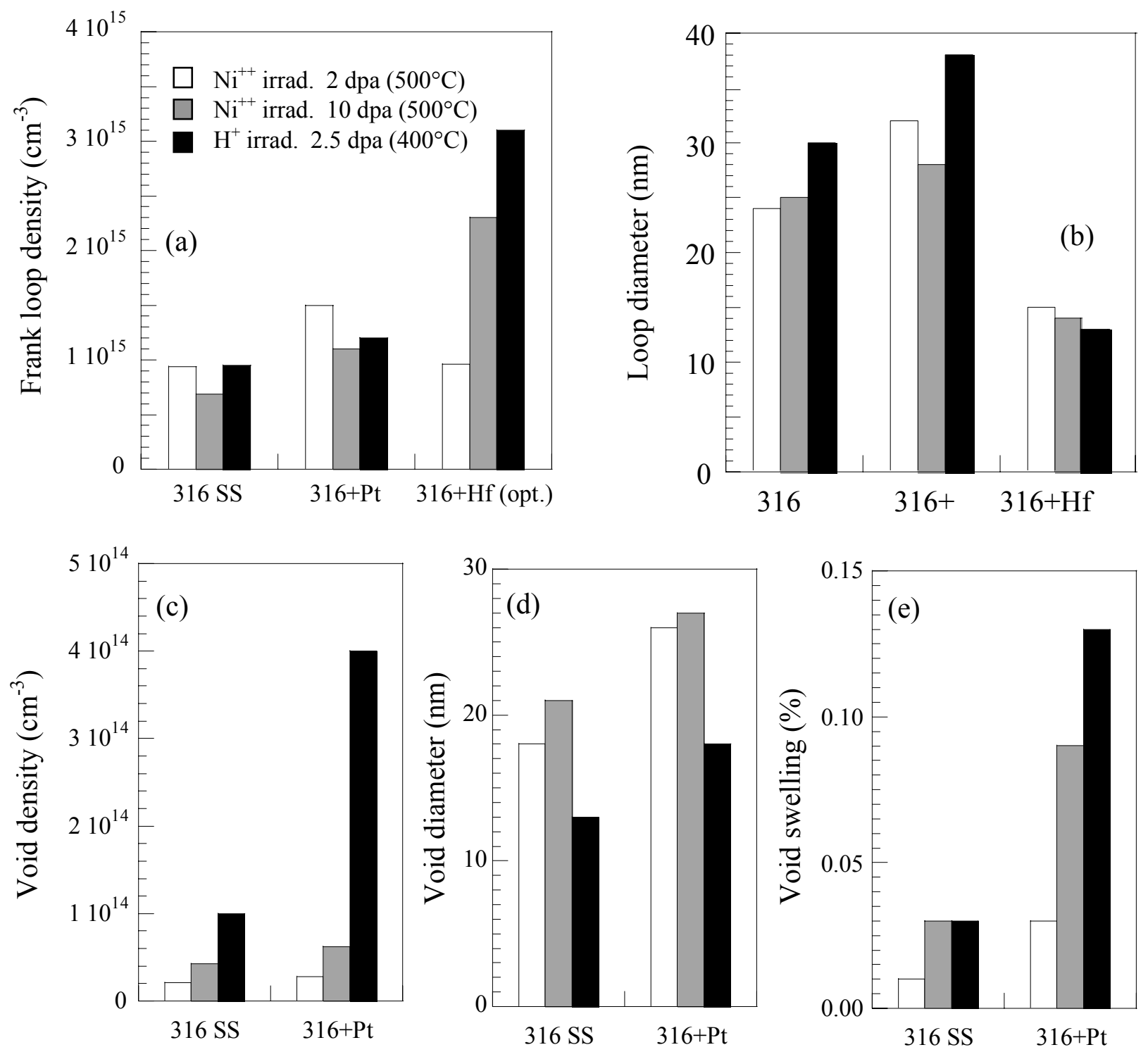

Figure 25. Comparison of irradiated microstructure and void swelling between Ni ion irradiation at $500^{\circ} \mathrm{C}$ to doses of $2 \mathrm{dpa}$ and $10 \mathrm{dpa}$ and proton irradiation at $400^{\circ} \mathrm{C}$ to a dose $2.5 \mathrm{dpa}$ in alloys $316 \mathrm{SS}, 316+\mathrm{Pt}$ and 316+Hf (optimized). 

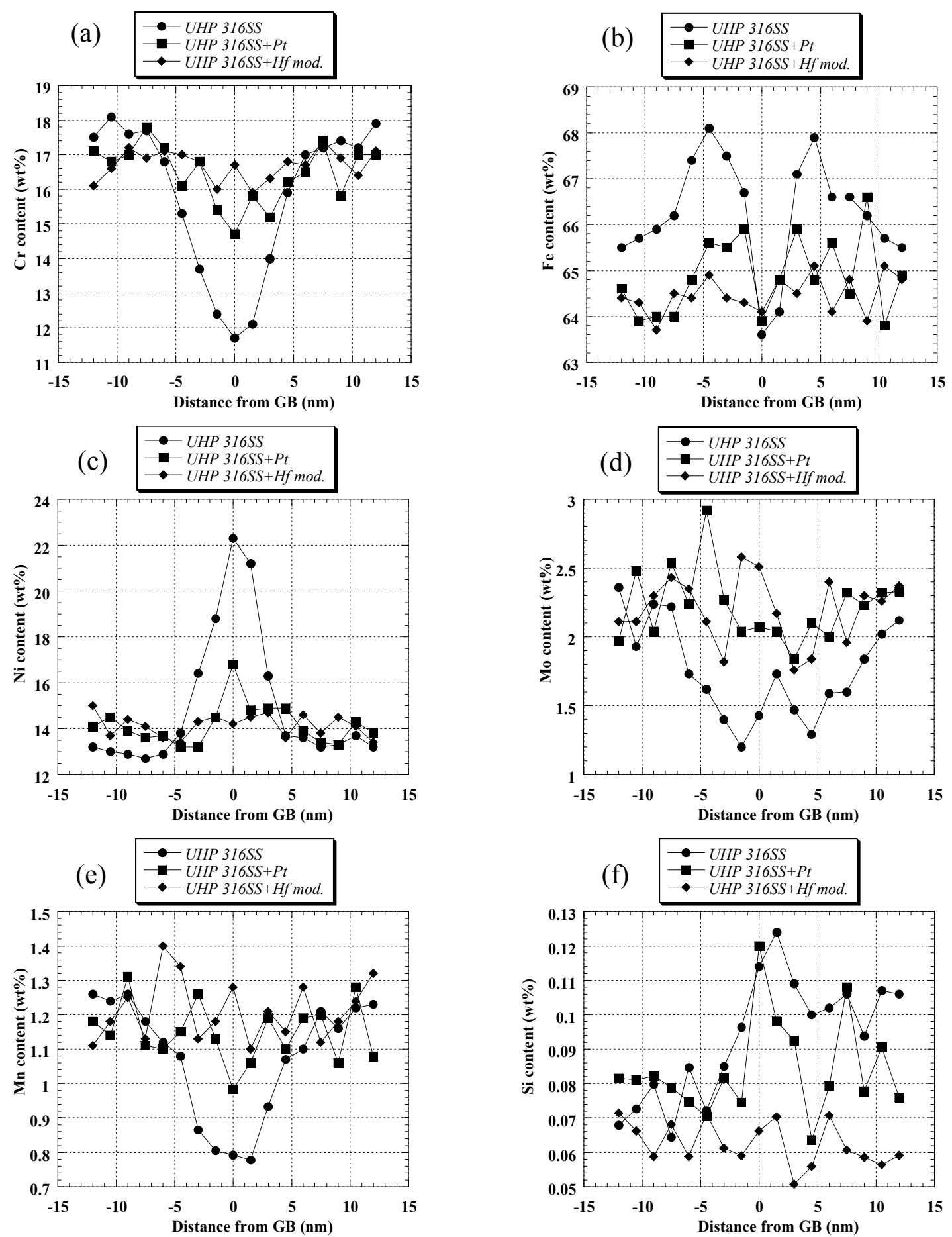

Figure 26. Comparative (a) $\mathrm{Cr}$, (b) $\mathrm{Fe}$, (c) $\mathrm{Ni}$, (d) $\mathrm{Mo}$, (e) $\mathrm{Mn}$ and (f) Si typical grain boundary composition profiles for UHP 316SS, UHP 316SS+Pt and UHP 316SS+Hf mod. alloys proton-irradiated to 2.5 dpa at $400^{\circ} \mathrm{C}$. 


\section{Mechanical Behavior and Stress Corrosion Cracking}

\section{Radiation Hardening}

The measured hardness of $316 \mathrm{SS}, 316 \mathrm{SS}+\mathrm{Pt}$ and $316 \mathrm{SS}+\mathrm{Hf}$ optimized alloys before and after proton irradiation to $2.5 \mathrm{dpa}$ at $400^{\circ} \mathrm{C}$ are listed in Table 10 . The hardness value of the irradiated condition was subtracted from that of the nonirradiated condition to arrive at a hardness increase due to irradiation. The yield strength increase due to irradiation was also estimated using the following empirical relation:

$$
\Delta \sigma_{\mathrm{y}}=3.55 \Delta \mathrm{H}_{\mathrm{V}}
$$

For the $316 \mathrm{SS}$ alloy, the hardness increase at $2.5 \mathrm{dpa}$ was determined to be $133 \mathrm{~kg} / \mathrm{mm}^{2}$, corresponding to an estimated increase in the yield strength of $472 \mathrm{MPa}$. Unexpectedly, $316 \mathrm{SS}+\mathrm{Pt}$ and $316 \mathrm{SS}+\mathrm{Hf}$ optimized alloys exhibit a significantly smaller increase in hardness than the $316 \mathrm{SS}$ alloy at $2.5 \mathrm{dpa}$.

\section{Irradiation-Assisted Stress Corrosion Cracking}

The results of the CERT tests performed in normal $\left(0.2 \mathrm{ppm} \mathrm{O}_{2}\right)$ water chemistry at $288^{\circ} \mathrm{C}$ on the three alloys proton-irradiated to $2.5 \mathrm{dpa}$ as well as on an unirradiated $316 \mathrm{SS}$ alloy are summarized in Table 11. The strain-to-failure, failure mode, number of intergranular surface cracks and total crack length in the irradiated region were tabulated for each sample. The 316SS+Pt specimen irradiated to 2.5 dpa exhibited the lowest strain to failure but failed in the nonirradiated region in a transgranular ductile way. The strain to failure of this specimen is therefore not relevant. The deformation behavior of the three other specimens is compared in Figure 27.

Table 9. Results of grain boundary composition measurements of 316SS, 316SS+Pt and $316 \mathrm{SS}+\mathrm{Hf}$ mod. alloys proton-irradiated to $2.5 \mathrm{dpa}$ at $400^{\circ} \mathrm{C}$.

\begin{tabular}{|c|c|c|c|c|c|c|c|c|c|c|}
\hline & \# $\boldsymbol{G B}$ & \# GB meas. & $\mathrm{Fe}$ & $\mathrm{Cr}$ & $\mathrm{Ni}$ & Mo & $M n$ & Si & $P t$ & $H \boldsymbol{f}$ \\
\hline \multicolumn{11}{|l|}{ UHP 316SS } \\
\hline Avg. GB comp. & 2 & 6 & 63.3 & 12.4 & 22 & 1.4 & 0.8 & 0.1 & & \\
\hline Bulk comp. & & & 65.5 & 17.5 & 13.3 & 2.4 & 1.3 & 0.07 & & \\
\hline \multicolumn{11}{|l|}{$\underline{U H P} 316 S S+P t$} \\
\hline Avg. GB comp. & 2 & 6 & 64.8 & 15.4 & 15.7 & 2 & 1 & 0.07 & 1 & \\
\hline Bulk comp. & & & 65.2 & 16.9 & 13.6 & 2 & 1.2 & 0.08 & 1 & \\
\hline \multicolumn{11}{|c|}{ UHP 316SS $+H f$ mod. } \\
\hline Avg. GB comp. & 2 & 6 & 64 & 15.8 & 15.5 & 2.5 & 1.1 & 0.08 & & 1 \\
\hline Bulk comp. & & & 64.5 & 16.4 & 14.4 & 2.4 & 1.3 & 0.06 & & 0.9 \\
\hline
\end{tabular}


Table 10. Results of microhardness measurements of 316SS, 316SS+Pt and $316 \mathrm{SS}+\mathrm{Hf}$ mod. alloys proton irradiated to $2.5 \mathrm{dpa}$ at $400^{\circ} \mathrm{C}$.

\begin{tabular}{ccccc}
\hline & $\begin{array}{c}\text { Hv unirr. } \\
\left(\mathrm{kgmm}^{-2}\right)\end{array}$ & $\begin{array}{c}\text { Hv irr. } \\
\left(\mathrm{kgmm}^{-2}\right)\end{array}$ & $\begin{array}{c}\Delta H \boldsymbol{H} \\
\left(\mathrm{kgmm}^{-2}\right)\end{array}$ & $\begin{array}{c}\Delta \sigma \\
(\mathrm{MPa})\end{array}$ \\
UHP 316SS & 169 & 302 & 133 & 472 \\
UHP 316SS+Pt & 177 & 260 & 83 & 294 \\
UHP 316SS+Hf mod. & 189 & 285 & 96 & 340 \\
\hline
\end{tabular}

Table 11. The results of CERT tests in BWR water chemistry for proton irradiated

\begin{tabular}{|c|c|c|c|c|}
\hline \multirow{3}{*}{+2} & \multirow{2}{*}{$\begin{array}{c}\text { Strain to failure } \\
\text { (\%) }\end{array}$} & \multirow[t]{2}{*}{ Failure Mode } & \multicolumn{2}{|c|}{ Surface cracks in irradiated region } \\
\hline & & & Number & Total length $(\mu \mathrm{m})$ \\
\hline & 36 & TG ductile & None & 0 \\
\hline UHP 316SS $2.5 \mathrm{dpa}$ & 24 & $\mathrm{IG}+\mathrm{TG}$ ductile & 10 & 13000 \\
\hline UHP 316SS +Pt 2.5 dpa & $19 *$ & TG ductile* & 5 & 8000 \\
\hline UHP 316SS+Hf mod. $2.5 \mathrm{dpa}$ & 32 & TG ductile & None & 0 \\
\hline
\end{tabular}

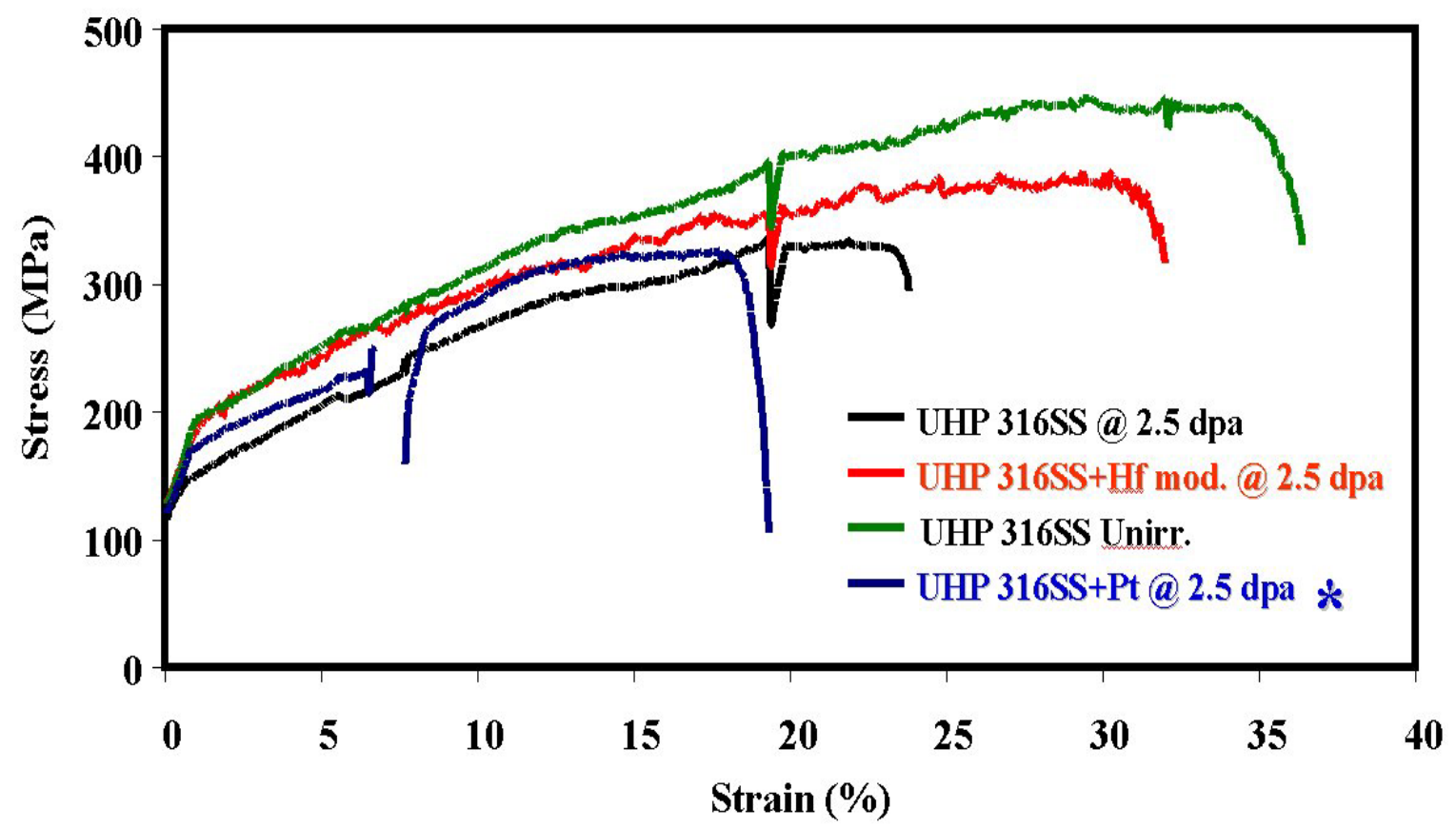

Figure 27. Stress as a function strain for SCC test of the unirradiated $316 \mathrm{SS}$ and proton irradiated 316 $\mathrm{SS}, 316+\mathrm{Pt}$ and $316+\mathrm{Hf}$ (optimized) alloys tested at $288^{\circ} \mathrm{C}$ in BWR water. 
As expected, no environmentally assisted cracking phenomenon was observed for the non-irradiated 316SS alloy. This alloy failed at the largest strain in a fully ductile manner by microvoid coalescence. In contrast, the $316 \mathrm{SS}$ alloy irradiated to $2.5 \mathrm{dpa}$ was found to be extremely sensitive to IASCC. This alloy exhibited a loss of ductility of $12 \%$ in comparison to the $316 \mathrm{SS}$ non-irradiated alloy that failed at $\sim 37 \%$ strain. In addition, cracking was purely intergranular in the irradiated region, i.e. in the first $40 \mu \mathrm{m}$, and then was typically ductile trangranular through the non-irradiated base metal. It should be mentioned here that intergranular cracking was also observed occasionally far beyond the $40 \mu \mathrm{m}$ of the irradiated region. This observation suggests that $316 \mathrm{SS}$ is also sensitive to SCC in BWR water chemistry but that the existence of a critical defect is a necessary condition for its occurrence.

The addition of Hf was observed to be extremely beneficial to IASCC resistance of $316 \mathrm{SS}$ alloys. The $316 \mathrm{SS}+\mathrm{Hf}$ optimized alloy proton-irradiated to $2.5 \mathrm{dpa}$ exhibited a significantly higher strain-to-failure than did the 316SS alloy proton-irradiated to $2.5 \mathrm{dpa}$. No intergranular surface cracks were observed in the irradiated region. The fracture mode was completely ductile, suggesting that the addition of Hf suppressed IASCC. Finally, the addition of Pt was not found to mitigate IASCC of 316SS alloys. The $316 \mathrm{SS}+\mathrm{Pt}$ alloy proton-irradiated to $2.5 \mathrm{dpa}$, like the $316 \mathrm{SS}$ alloy, exhibited a significant number of intergranular surface cracks in the irradiated regions.

\section{Strength Effects on IGSCC}

Radiation-induced strengthening caused by loop damage is a primary property impacted by the development of displacement damage microstructure. The effect of alloy strength on SCC is being evaluated using crack-growth testing of cold-worked or warm-worked, non-irradiated stainless steels. Crack growth is measured in compact-tension specimens using a unique technique for promoting crack growth. The method enables measurements of crack-growth rates as low as $10^{-8} \mathrm{~mm} / \mathrm{s}$. A key aspect to the method is to induce growth of a uniform well-defined crack front by using load cycling initially. These tests require long-term testing in an autoclave of controlled environment and mechanical state. To optimize use of a single sample, several tests are performed in sequence experiencing multiple changes in environment to assess effects on SCC crack growth.

In Year 2, SCC crack-growth rate measurements were completed in $288^{\circ} \mathrm{C}, 320^{\circ} \mathrm{C}$, and $340^{\circ} \mathrm{C}$ pure water for deformation-hardened $316 \mathrm{~L} \mathrm{SS}$. In addition, collaborative work on a 304L SS has been performed under similar conditions. While the microstructural origins of irradiation strengthening are different than that produced by cold work, SCC data show a pronounced and similar effect of both methods for increasing the yield strength. However, more detailed examinations of irradiation strengthening are needed.

The principal findings from these tests are (1) strength enhances the crack growth in both oxidizing and non-oxidizing water, (2) crack-growth rate increases with an increase in temperature from $288^{\circ} \mathrm{C}$ to $340^{\circ} \mathrm{C}$ in non-oxidizing water, and (3) crack-growth rates are not related to martensite phase formation or hydrogen. Therefore, it is expected that irradiation-induced strength and increasing service temperature will contribute to 
enhanced IASCC growth rates. Control of irradiation microstructure evolution will aid in the management of IASCC for next generation reactors.

\section{Crack-Growth Measurement Technique}

The compositions of the types 304L and 316L stainless steels being evaluated at GECRD are listed in Table 12. The materials were rolled at $+140{ }^{\circ} \mathrm{C}$ or $-40^{\circ} \mathrm{C}$ by $10 \%, 20 \%$, or $50 \%$. Equal reduction, cross-rolling passes were used for the $20 \%$ and $50 \%$ reductions in area. Since rolling at $<10 \%$ per pass produces very inhomogeneous deformation, the $10 \%$ reduction was produced in a single pass.

Stainless steel plate material was machined into $0.5 \mathrm{~T}$ compact tension (CT), crackgrowth specimens with 5\% side grooves on each side. The CT specimens were instrumented with platinum current and potential probe leads for dc potential drop measurements of crack length. In this technique, current flow through the sample is reversed about once per second primarily to reduce measurement errors associated with thermocouple effects and amplifier offsets. The computer control of current reversal, data acquisition, data averaging techniques, and the relationship between measured potential and crack length have been established. Depending on the test conditions, data were stored in a permanent disk file approximately once every 0.3 to $6 \mathrm{~h}$. In addition to the data record number, total elapsed and incremental time, and crack length, the system measured and stored the temperature, current corrosion potential, effluent dissolved oxygen, effluent conductivity, load and time/date. Statistical information on temperature and current fluctuations is also recorded.

Initial crack extension from the machined notch by 0.5 to $1.0 \mathrm{~mm}$ was typically performed in air or in the environment at $\geq 1 \mathrm{~Hz}$. This was done at a load ratio $\left(\mathrm{K}_{\min } /\right.$ $\left.\mathrm{K}_{\max }\right) \mathrm{R}=0.3$ to 0.5 and a $\mathrm{K}_{\max }$ somewhat below the test value of about $27.5 \mathrm{MPa} \sqrt{\mathrm{m}}_{\text {, }}$, where $\mathrm{K}$ is the stress intensity factor and $\mathrm{R}$ is the ratio of the minimum to maximum stress intensity. When specimens were tested in tandem, they were fatigue pre-cracked individually in air, then loaded together into the autoclave for subsequent transitioning from transgranular fatigue conditions to IGSCC conditions.

Testing was performed using Instron Model 1362 servo-electric testing machines or Model 1350 servo-hydraulic machines equipped with a single stage, slow strain servovalve to ensure optimal (non-noisy) response. All systems are equipped with Model 8500 digital controls that provide improved machine control and full computer interface/control capabilities. The potential drop software has been modified to interface

Table 12. Composition of Stainless Steels used for SCC Crack-Growth Tests, wt $\%$

\begin{tabular}{|l|c|c|c|c|c|c|c|c|c|c|}
\hline $\begin{array}{c}\text { alloy } \\
\text { (heat) }\end{array}$ & Fe & $\mathbf{C}$ & $\mathbf{N}$ & $\mathbf{P}$ & $\mathbf{S}$ & $\mathbf{C r}$ & $\mathbf{N i}$ & Mo & Mn & Si \\
\hline 304L & & & & & & & & & & \\
\hline GrandGulf & bal. & 0.015 & 0.069 & 0.015 & 0.010 & 18.60 & 8.89 & 0.33 & 1.78 & 0.45 \\
\hline 316L & & & & & & & & & & \\
\hline A14128 & bal. & 0.014 & 0.085 & 0.015 & 0.001 & 17.64 & 12.40 & 2.60 & 1.78 & 0.47 \\
\hline
\end{tabular}


with the Instron 8500 electronics and to automate several facets of the load and waveform setup procedure. Automatic K control was employed in most tests, with load corrections applied after very small increases in stress intensity, typically $<0.1 \%$.

Crack-growth rates can be treated as statistically significant when the crack-growth increment is at least 10 times the limiting resolution of the technique, which is typically $<0.002$ to $0.005 \mathrm{~mm}$. Thus, crack length increments are typically $\geq 0.05 \mathrm{~mm}$, although for very low growth rate conditions, smaller increments are occasionally used to reduce testing time from several months per datum to several weeks. The correlation coefficients from linear regression analyses of the crack lengths vs. time data from which growth rates are calculated are typically $>0.98$.

Optimization of the reversed DC potential drop technique has provided incremental crack length resolution on a micron scale. For example, even without compensation for minor fluctuations in temperature and applied current, the typical resolution on a 1TCT specimen in $288^{\circ} \mathrm{C}$ water is $2-5 \mu \mathrm{m}$-h, corresponding to $\approx 1 \mu \mathrm{m}$ resolution if data are averaged over a 5-h period. Subtle changes in apparent crack length during cyclic loading can also be observed.

An analysis of the accuracy of the technique based on eleven Type 304L, 316L and $316 \mathrm{NG}$ stainless steel $1 \mathrm{TCT}$ specimens tested in $288^{\circ} \mathrm{C}$ water revealed that the crack depth determined by potential drop was, on average, $2.2 \%$ below the actual depth. The worst case error was $11 \%$ on $20 \mathrm{~mm}$ of growth; the errors for 6 of 11 specimens were $<2 \%$. Similar results have also been observed for sensitized Type 304 stainless steel and turbine steel specimens.

Tests were performed in 4-liter stainless steel autoclaves starting at $288^{\circ} \mathrm{C}$ and $10.3 \mathrm{MPa}$ (1500 psi). The autoclave effluent water was continuously monitored for solution conductivity using a second Sybron Barnstead Model PM-512 meter and periodically monitored for dissolved oxygen using an Orbisphere Model 2606. A zirconia membrane reference electrode was employed for continuous measurement of the corrosion potential.

\section{Crack-Growth Testing Results}

The effect of alloy strength on crack growth in oxidizing and nonoxidizing water was clearly established as shown in Figures 28 and 29, respectively. Crack-growth rates were documented for stainless steel alloys thermally mechanically processed to yield strengths from 160 to $760 \mathrm{MPa}$. This range is similar to irradiation strengthening and allowed evaluation of the isolated influence of radiation strengthening on SCC crack-growth rate. The addition of hydrogen to the water strongly suppressed the crack-growth but the strength dependence was similar when comparing Figure 28 with Figure 29. In addition, variation in the martensite content (cold work versus warm work) did not affect the dependence of crack-growth rate on strength.

Multiple growth rates were obtained by testing a single sample using a series of changes in the chemical environment and temperature. An example crack-growth run at multiple 
conditions is shown in Figure 30. Changes in crack growth occur with changes in potential and temperature. The total test time was 6000 hours ( 9 months).

A total of 25 crack-growth-rate measurements were made in the strength effect study. The potential of the environment was controlled by addition of either $\mathrm{O}_{2}$ or $\mathrm{H}_{2}$ and by control of the water temperature. The material condition was varied by cold-working to

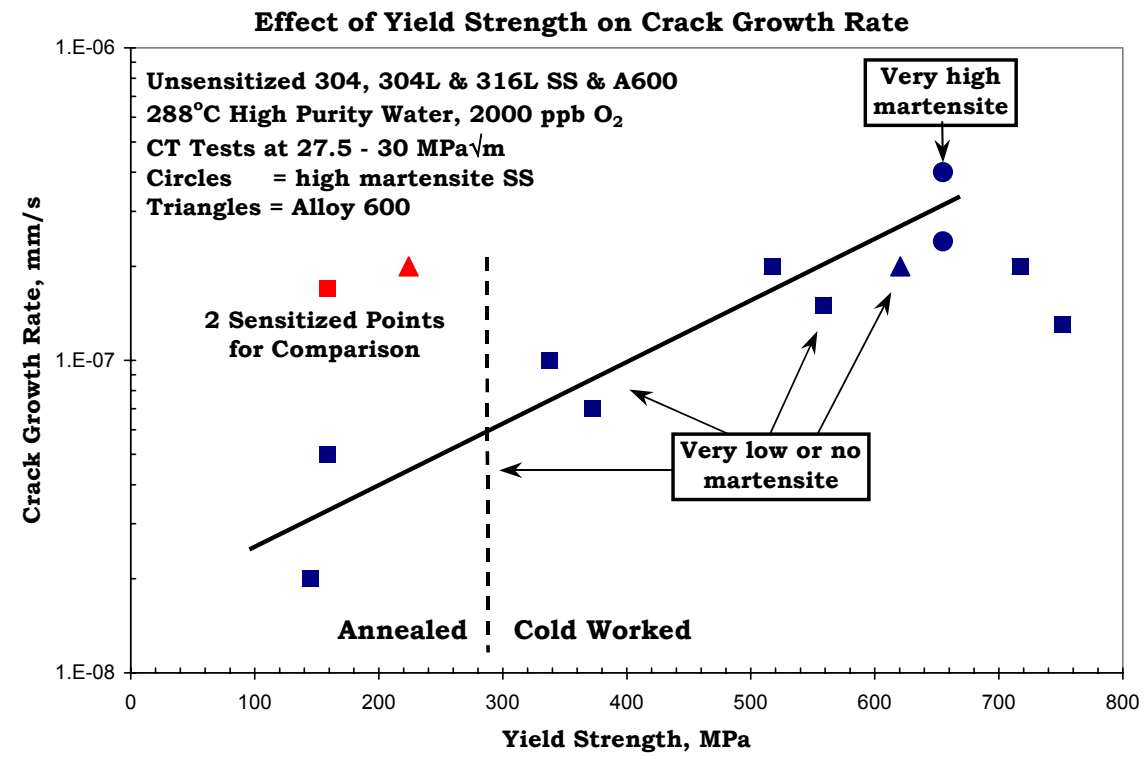

Figure 28. Effect of yield strength and martensite on the stress corrosion crack-growth rate on stainless steel and alloy 600 in $288^{\circ} \mathrm{C}$, high purity water $(<0.10 \mu \mathrm{S} / \mathrm{cm}$ outlet $)$ containing $2000 \mathrm{ppb} \mathrm{O}_{2}$.

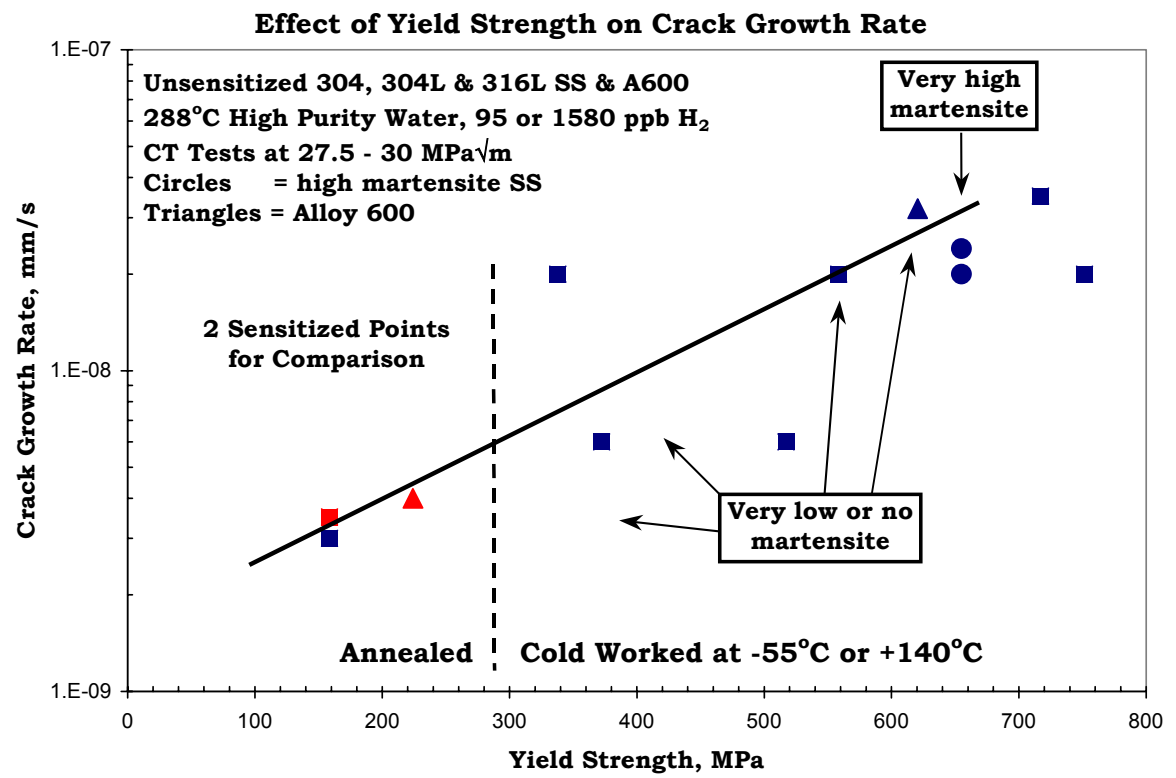

Figure 29. Effect of yield strength and martensite on the stress corrosion crack-growth rate on stainless steel and alloy 600 in $288^{\circ} \mathrm{C}$, high purity water $(\approx 0.06 \mu \mathrm{S} / \mathrm{cm}$ outlet $)$ containing 95 or $1580 \mathrm{ppb} \mathrm{H}_{2}$. 


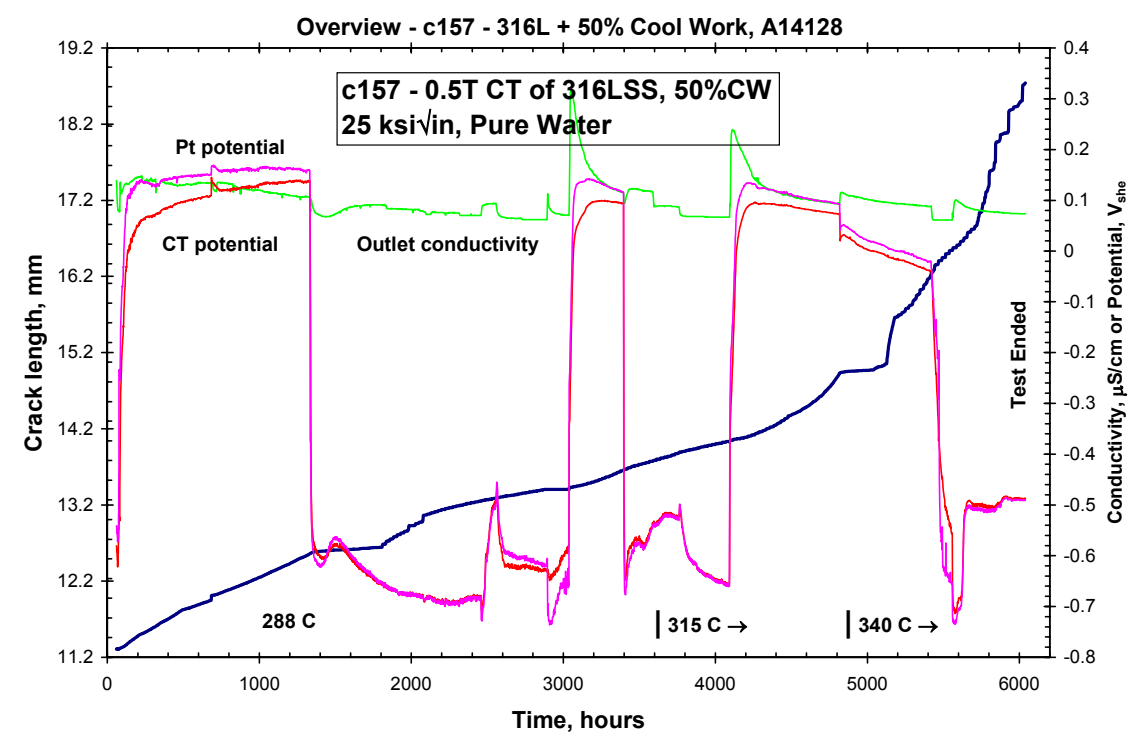

Figure 30. Overview of CT specimen c157, Type 316L SS (heat A14128) cool rolled 50\% at $+140^{\circ} \mathrm{C}$.

$0,10,20$ or $50 \%$ and by working at either $+140^{\circ} \mathrm{C}$ or $-40^{\circ} \mathrm{C}$. The level of cold work established the material yield strength and the temperature of cold working established the proportion of martensite. Martensite has been postulated as a controlling factor for environmental cracking. The present results clearly demonstrate that it is not a significant factor and should not be a influencing mechanism during IASCC.

Increasing temperature promotes crack-growth rate as shown in Figure 31. An activation energy of $64.2 \mathrm{~J} / \mathrm{mole}$ was calculated. This activation energy is much lower than for solid state diffusion $(250 \mathrm{~J} / \mathrm{mole})$ which indicates that creep does not significantly control crack-growth rate. Therefore, radiation-enhanced creep is not an important influence on crack growth during IASCC.

The fundamental description of crack growth kinetics is mapped as a function of environmental and material conditions in Figure 32. Conventional crack-growth understanding is that grain boundary $\mathrm{Cr}$ depletion is a necessary condition for IGSCC in oxidizing water, i.e., high potential. The small data points at high oxygen represent crack-growth rates measured in sensitized (Cr depleted boundaries). The large symbols indicate the rates obtained for cold-worked and non-sensitized alloys. Remarkably, the crack-growth rates are comparable.

Stainless steel is intrinsically susceptible to cracking and there is no assurance that eliminating any single cracking mechanism will assure immunity. Sensitization and alloy strength both contribute to cracking. In the continuum understanding of cracking, it is clear that radiation-induced $\mathrm{Cr}$ depletion at grain boundaries is not the singular cause for enhanced susceptibility. Radiation strengthening cause by matrix microstructure also must be included as a controlling factor. 


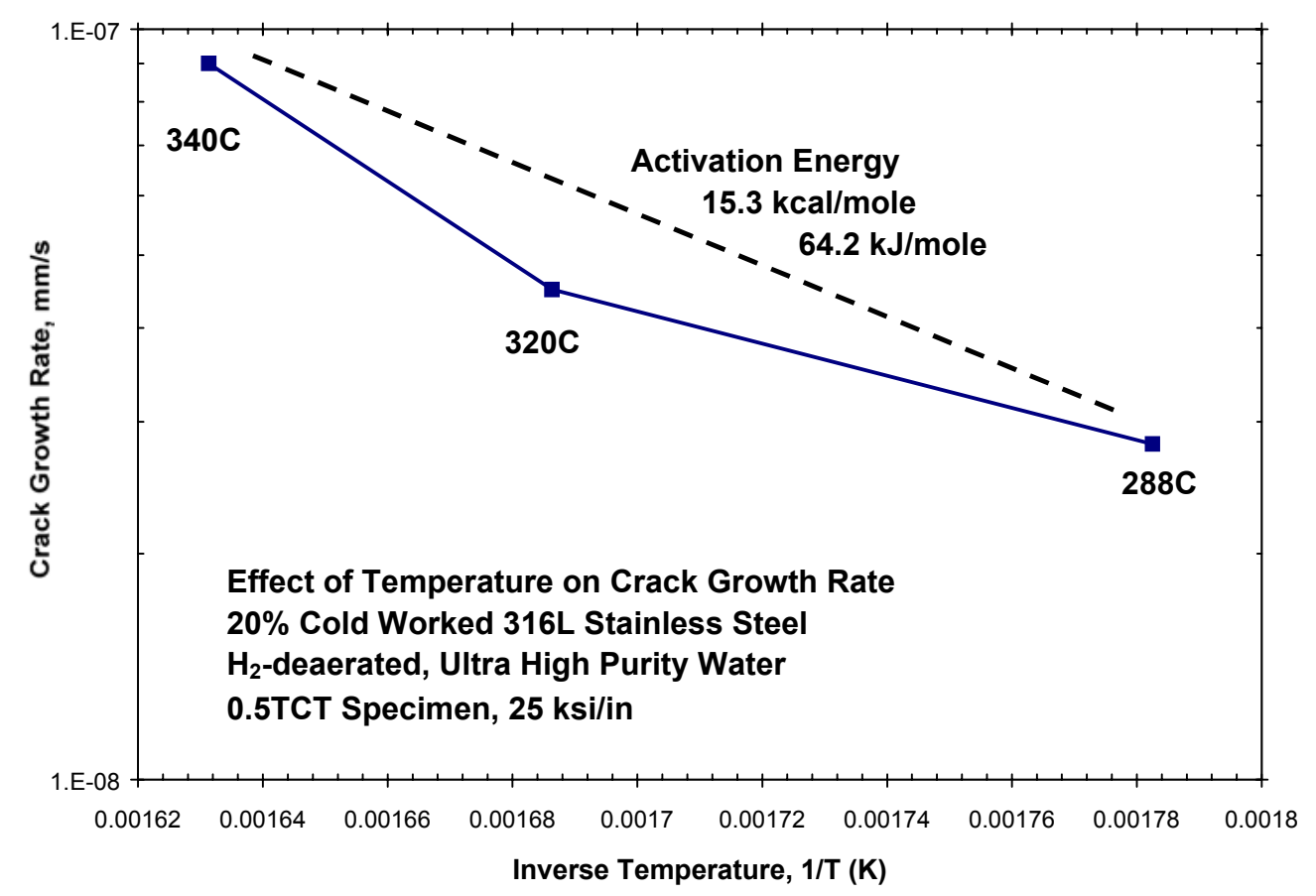

Figure 31. Crack-growth rate vs. temperature for type $316 \mathrm{~L} \mathrm{SS} 20 \%$ cold rolled at $+140^{\circ} \mathrm{C}$ and tested in $\mathrm{H}_{2}$ deaerated, pure water.

At low potentials, i.e. $-0.5 \mathrm{~V}_{\text {she }}$, cold working is shown to induce higher growth rates compared to the standard GE PLEDGE predicted influence of potential. The data support the conclusion that radiation strengthening affects crack-growth rates in hydrogenated environments.

Crack-growth rate is inversely related to hydrogen permeation rate as shown in Figure 33. The crack-growth rates and coolant concentrations are plotted as measured in the same experiment. The hydrogen permeation rate is shown to increase with hydrogen concentration as expected. The crack-growth rate is suppressed by the addition of $\mathrm{H}_{2}$ (and the elimination of $\mathrm{O}_{2}$ ) clearly showing that hydrogen assisted cracking is not an important mechanism in this cold worked strengthened alloy. It is concluded that the effect of radiation strengthening on cracking, i.e. IASCC, is not enhanced by hydrogen. 


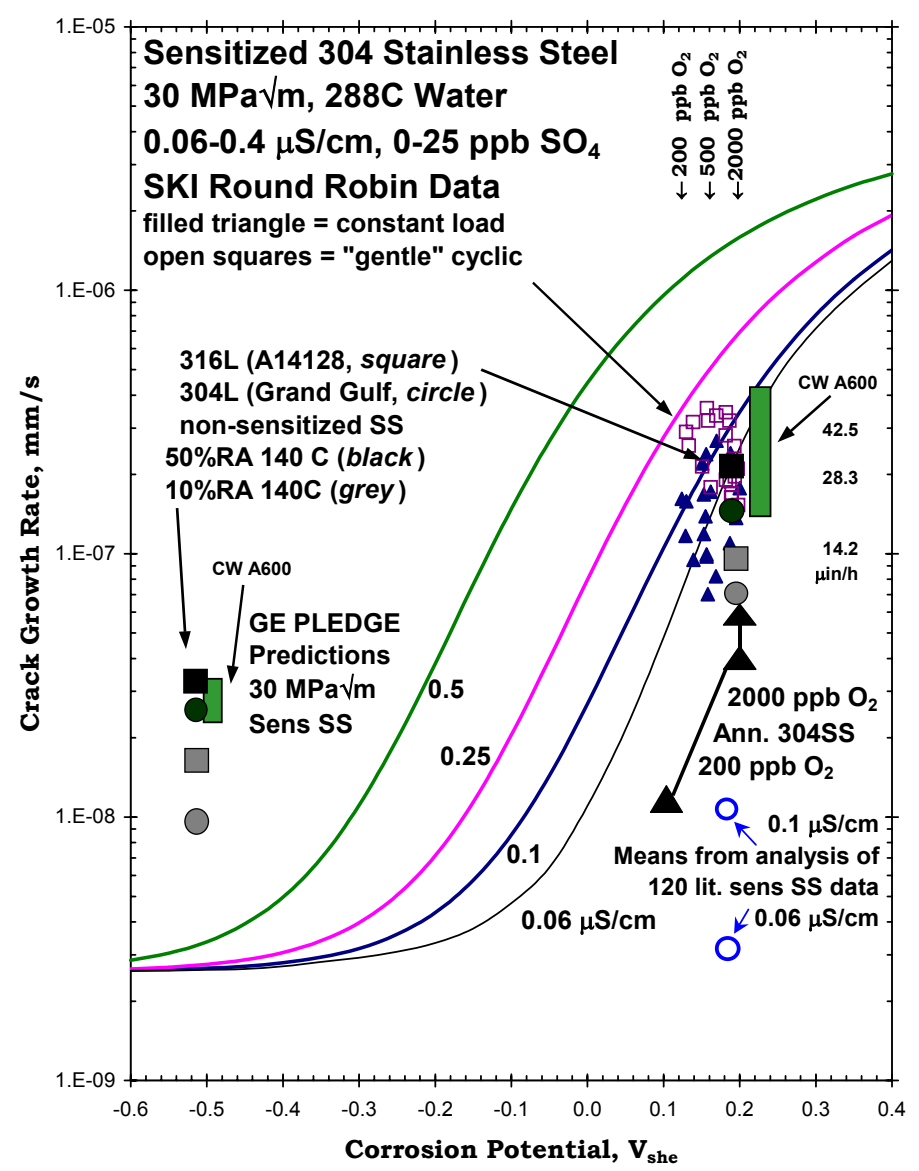

Figure 32. Crack-growth rate vs. corrosion potential for cool rolled types 304L and 316L SS tested in 288 ${ }^{\circ} \mathrm{C}$ pure water. The numerous data at high potential and $\approx 10^{-7} \mathrm{~mm} / \mathrm{s}$ were obtained in the SKI/EPRI Round Robin, and the three black triangles were obtained in a separate GE CRD program on the same (SKI) material after solution annealing. The large circles and squares represent the best estimate of the observed behavior in this program

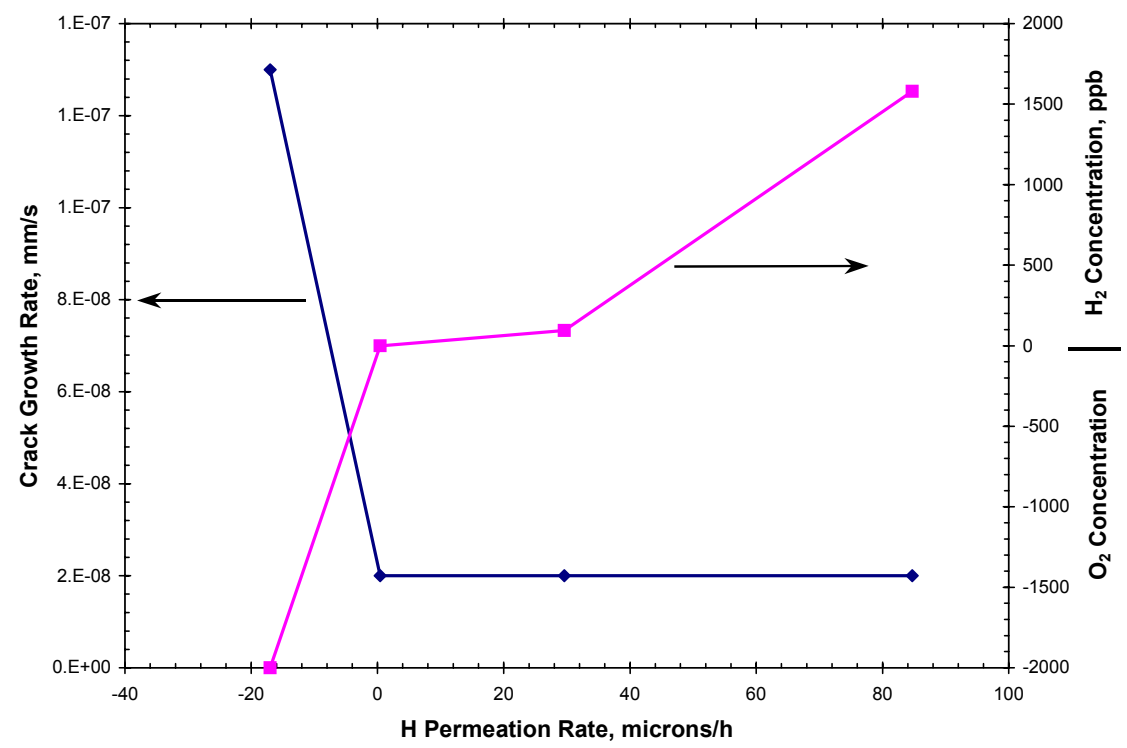

Figure 33. Hydrogen permeation rate (measured as a pressure increase) vs. crack -growth rate and vs. coolant $\mathrm{H}_{2}\left(\right.$ and $\left.\mathrm{O}_{2}\right)$ concentration in unsensitized Type $304 \mathrm{~L}$ stainless steel in $288^{\circ} \mathrm{C}$ high purity water. 